\title{
Role of physico-chemical environment on gastropod assemblages at hydrothermal vents on the East Pacific Rise (13 ${ }^{\circ}$ /EPR)
}

\author{
Marjolaine Matabos ${ }^{1}$, Nadine Le Bris ${ }^{2}$, Sophie Pendlebury ${ }^{3}$ and Eric Thiébaut ${ }^{4,}$ *
} ${ }^{1}$ Muséum National d'Histoire Naturelle, Département Milieux et Peuplements Aquatiques, UMR 5178 BOME
(MNHN, UPMC, CNRS), CP53, 61 rue Buffon, F-75231 Paris cedex 05, France
${ }^{2}$ Ifremer, Département Etude des Ecosystèmes Profonds, BP70, F-29280 Plouzané, France
${ }^{3}$ Southampton Oceanography Centre, European Way, Southampton, SO14 3ZH, UK
${ }^{4}$ Université Pierre et Marie Curie-Paris 6, Station Biologique de Roscoff, UMR 7144 (CNRS, UPMC), BP 74, F-
29682 Roscoff cedex, France

*: Corresponding author : Thiébaut E., email address : thiebaut@sb-roscoff.fr

\begin{abstract}
:
Deep-sea hydrothermal vents display extreme and highly variable environmental conditions that are expected to be among the most important factors structuring associated benthic populations and communities. We tested this assumption, focusing on the distribution of gastropods, as well as on the demographic population structure and reproductive biology of one dominant gastropod species in zones characterized by alvinellid polychaetes and vestimentiferan tubeworms. A total of 14 biological samples from both types of habitats were collected at three sites on the East Pacific Rise $13^{\circ} \mathrm{N}$ vent field in May 2002. At all vents except one, the physico-chemical environment was described in two steps: (1) $\mathrm{pH}$, total sulphide and reduced iron concentrations have been measured in situ in Alvinella habitats and correlations to temperature were assessed at the scale of each sampled vent; and (2) assuming the consistency of these relationships within a single edifice, ranges of physico-chemical factors were estimated for each biological sample from the corresponding fine scale temperature measurements. A total of 11 gastropod species were identified from all samples and 2 main faunal assemblages were distinguished: one dominated by Lepetodrilus elevatus in the alvinellid zone as well as in the vestimentiferan zone, and one dominated by the peltospirids Nodopelta heminoda, $N$. subnoda and Peltospira operculata confined to the alvinellid zone. Peltospirid gastropods were dominant over lepetodrilid gastropods in the more acidic, sulphide-richer, and hotter environments. Although this pattern could be related to specific physiological tolerances to temperature and sulphide toxicity, the weak correlation between community structure and physico-chemical variables suggests that additional factors are also involved. Particularly, the low species richness and the overwhelming dominance of $L$. elevatus in one faunal assemblage suggest that this species may outcompete peltospirids and greatly affect community structure. This hypothesis is supported by large differences in the demographic structure and reproductive biology of $L$. elevatus between the 2 faunal assemblages.
\end{abstract}

Keywords: physico-chemical environment; gastropod assemblages; hydrothermal vents; East Pacific Rise 


\section{INTRODUCTION}

Deep-sea hydrothermal vents host highly productive communities fueled primarily by chemosynthetic microbial production and characterized by low species richness but high proportion of endemic species, and a large biomass in contrast with the surrounding deep-sea floor. The limited lifespan of vent sites, related to sea-floor spreading rate and frequent volcanic eruptions, leads to the creation of ephemeral and transient habitats, patchily distributed around vent sites separated from 10s of meters to 100s of kilometers. Within a single vent site, the high spatio-temporal variability of environmental conditions in terms of temperature, $\mathrm{pH}$, and concentrations of oxygen, sulphide and metals (Johnson et al., 1994; Sarradin et al., 1998; Le Bris et al., 2003, 2006b) produces a mosaic of habitats with contrasted biological characteristics (Sarrazin et al., 1997; Shank et al., 1998; Sarrazin \& Juniper, 1999). Organisms are distributed in different assemblages around the vent, and their composition varies in space and time in relation with the decreasing gradient of fluid exposure, the physical structure of the mineral substrate and the temporal dynamics of vent colonization (Sarrazin et al., 1997; Shank et al., 1998). On the East Pacific Rise (EPR), 4 main megafaunal assemblages have been described: (i) alvinellid polychaete colonies restricted to the most active areas of chimney walls with high-temperature emissions, (ii) vestimentiferan tubeworm assemblages in recent and active diffuse flow areas, (iii) bivalve assemblages in moderate and older diffuse flow areas and (iv) suspension-feeder assemblages dominated by serpulid polychaetes and barnacles at the periphery of vents in seawater with little or no hydrothermal influence (Jollivet, 1996; Shank et al., 1998).

The influence of environmental factors in shaping hydrothermal communities appears quite complex, and some non-exclusive hypotheses are still debated. According to the correspondence between physico-chemical gradients and faunal zonation, several ecological studies have related the variability of faunal composition in space and time to changes in 
environmental conditions, putting much emphasis on physiological tolerances and nutritional requirements of organisms (Sarrazin et al., 1997; Shank et al., 1998). In this context, two physico-chemical parameters were commonly referred to as potentially determinant: temperature (Bates et al., 2005; Mills et al., 2007), and sulphide which is both a major electron donor for chemoautotrophic microbes and a potent poison for aerobic organisms (Childress \& Fisher, 1992). However, more than total sulphide concentration, it was pointed out that differences in chemical speciation of sulphide among habitats may be a key-factor driving the distribution of species (Luther et al., 2001). Although total acid-volatile sulphide concentrations $\left(\mathrm{H}_{2} \mathrm{~S}+\mathrm{HS}^{-}+\mathrm{FeS}(\mathrm{aq})\right)$ was shown to be at least 5 times higher in an Alvinella pompejana colony than in a Riftia pachyptila clump, these authors found that FeS(aq) was the dominant sulphide phase in the former habitat while free sulphide $\left(\mathrm{H}_{2} \mathrm{~S}+\mathrm{HS}^{-}\right)$was the major form in the latter. FeS formation was therefore proposed to act as a sulphide detoxification mechanism in Alvinella colonies. The importance of this process depends largely on the dissolved iron to sulphide ratio which is known to be highly variable among habitats (Le Bris \& Gaill, 2007; Le Bris et al., 2006a), resulting of end-member fluid composition variability in space and time (Von Damm \& Lilley, 2004). Conversely, Govenar et al. (2005) showed that the structure and composition of the epifaunal community associated with different $R$. pachyptila clumps were remarkably similar between sites and independent of sulphide and iron concentrations. Likewise, Mullineaux et al. (2000) suggested that the settlement of the two vestimentiferan species, $R$. pachyptila and Oasisia alvinae, was independent of tolerances to physico-chemical conditions but rather facilitated by the occurrence of Tevnia jerichonana. While biotic interactions between organisms (i.e. facilitation, competition, predation) could be major determinants of community structure (Micheli et al., 2002), they were shown to vary along the gradient of flow intensity with facilitation processes occurring at the periphery of vents, where animal density is lower, and inhibition processes occurring in the high diffuse 
103 vent flow areas (Mullineaux et al., 2003). More recently, Mills et al. (2007) suggested that

104 most hydrothermal gastropod species are not exclusive to a specific megafaunal zone as they 105 may occupy specific microhabitats.

106 In other respects, physico-chemical conditions could also play a significant role on

107 population dynamics of deep-sea hydrothermal species (e.g. growth, survivorship, 108 reproduction) although very few studies addressed directly these questions (Mullineaux et al.,

109 1998; Copley et al., 2003; Kelly \& Metaxas, 2007). While reproductive cycles of lepetodrilids 110 were described to be quasi-continuous within females and asynchronous among females 111 (Pendlebury, 2004), Kelly \& Metaxas (2007) reported that the rate of gametogenesis of 112 Lepetodrilus fucensis could vary between habitat types. By controlling the abundance and the 113 turnover of local populations, one can expect that these spatial variations in biological 114 features may affect the intensity of biological interactions and the structure of benthic 115 communities.

116 On hydrothermal vents of the East Pacific Rise, the alvinellid polychaetes $A$.

117 pompejana and A. caudata inhabit the surface of active sulphide structures, presumably in the 118 most hypoxic and toxic conditions found in these environments (Le Bris \& Gaill, 2007), and 119 are known as the very first macrofaunal colonizers of new chimney habitats (Pradillon et al., 120 2005b; Taylor et al., 1999). In these extreme environmental conditions, biological adaptations 121 and community structure are expected to be mostly driven by biogeochemical processes 122 (Luther et al., 2001). However, most studies on processes involved in hydrothermal 123 community structure were conducted on mussel beds or vestimentiferan clumps (Micheli et 124 al., 2002; Mullineaux et al., 2003; Tsurimi \& Tunnicliffe, 2003; Van Dover, 2003; Govenar et 125 al., 2004; Dreyer et al., 2005) and faunal distribution in Alvinella colonies remains poorly 126 known (Desbruyères et al., 1998). Focusing on gastropods, which represent a major part of 127 vent fauna in terms of density and diversity in different habitats (Jollivet, 1996; Mills et al., 
2007) the aims of the present study were: (1) to better characterize the physico-chemical variability of habitats at the surface of $A$. pompejana colonies from the $13^{\circ} \mathrm{N}$-EPR vent field, from the assessment of, both, fine scale temperature ranges and correlations of temperature with chemical factors that were measured in situ; $\mathrm{pH}$, sulphide and iron concentrations ranges were thus determined over spatial scales as relevant as possible to the conditions experienced by gastropods; (2) to relate these environmental ranges to the variability in the composition of faunal assemblages at different scales; and (3) to assess the relationships between population biology and environmental conditions with Lepetodrilus elevatus as an example. This species was chosen as it displayed a wide distribution in hydrothermal habitats (Mills et al., 2007) and was reported to be a highly competitive species in hydrothermal faunal assemblages (Micheli et al., 2002). Additional samples from $R$. pachyptila clumps were also analysed for comparison with Alvinella habitats.

\section{MATERIALS AND METHODS}

\section{Study sites}

All physico-chemical and biological data were collected using the ROV Victor 6000 during the PHARE cruise carried out in May 2002 on the $13^{\circ} \mathrm{N}$ vent field along the East Pacific Rise (EPR). A hierarchical sampling method involving three spatial scales was undertaken for biological sampling (Table 1): (1) three vent sites, Genesis, Parigo and Elsa located at a depth of $\sim 2620 \mathrm{~m}$ and spaced by 100 s of meters, (2) two active sulphide structures (here referred to as 'vents') within each site at a scale of 10s of meters, and (3) one to six samples within each structure at a scale of meters. On the Genesis site, the PP12 vent is a small diffuser colonized by dense colonies of Alvinella pompejana at the top and Riftia pachyptila clumps around. On the opposite, the Hot 2 vent consisted in a large diffuse flow area on the side of a cliff with dense colonies of $R$. pachyptila and no A. pompejana colony 
153 present. The Parigo site was composed of three sulphide edifices including two small

154 diffusers and one tall chimney. The PP-Ph05(1) diffuser is covered by dense A. pompejana 155 colonies largely mixed with $R$. pachyptila tubes while the $\mathrm{PP}-\mathrm{Ph} 05(2)$ vent is a high chimney 156 with large colonies of A. pompejana or uncolonized surfaces on the upper half and $R$. 157 pachyptila clumps on its basis. On the Elsa site, PP-Ph01 vent is a massive black smoker 158 inhabited by large colonies of A. pompejana, at the top and intermediate height, and the 159 occurrence of large uncolonized surfaces. The Hot 3 vent is a 3 meter diameter white smoker 160 with dense colonies of A. pompejana at the top and $R$. pachyptila clumps around (Pradillon et 161 al., 2005a).

162

\section{Chemical analysis and definition of environmental parameters}

In a first step, extensive in situ measurements of temperature, $\mathrm{pH}$, total sulphide and reduced iron in the environment surrounding the gastropods, were conducted for each vent during different dives, using the submersible flow analyser Alchimist (AnaLyseur CHIMIque In $\mathrm{SiTu}$ ) combined to temperature and $\mathrm{pH}$ probes (Le Bris et al., 2000). Colorimetric flow injection analysis (FIA) methods were used to detect the most labile fraction of acid volatile sulphide S(-II) and labile forms of ferrous iron, Fe(II). S(-II) includes free sulphide forms, aqueous iron sulphide forms and freshly precipitated iron sulphide colloids (i.e. $\mathrm{HS}^{-}, \mathrm{H}_{2} \mathrm{~S}$, $\mathrm{FeS}(\mathrm{aq}), \mathrm{Fe}(\mathrm{HS})^{+}, \mathrm{FeS}(\mathrm{am})$ ) (Le Bris et al., 2003). In situ $\mathrm{pH}$ measurements were made using an autonomous deep-sea sensor (MICREL, France) equipped with a combined glass electrode and a miniaturized thermocouple that was specifically designed for these hydrothermal environments (Le Bris et al., 2001). Due to logistical constraints, no chemical data was available for the Riftia zone at Genesis Hot 2 vent which was therefore excluded from the analysis on the relationships between biological and environmental data. 
For each vent, this first step allowed to assess the relationships between temperature and sulphide, iron, and $\mathrm{pH}$ respectively, assuming the conservative mixing of a local hydrothermal fluid and seawater for a single alvinellid aggregation. This conservative mixing assumption was shown to be consistent for the water layer at the surface of an alvinellid colony in the vicinity of a local source (Le Bris et al., 2005). Hence, iron and sulphide concentrations could be estimated for each sample using the linear correlations established for

183 the corresponding hydrothermal structure. Similarly, $\mathrm{pH}$ was estimated from empirical 184 logarithmic correlations. In a second step, just before biological sampling, time-series measurements of temperature over duration ranging from 1 to 50 min were performed at 1 to 5 sampling locations in the biological sampling area using the Pt100 temperature probe of the

187 ROV Victor 6000 (Table 1). To ensure that they are representative of the micro-habitats 188 surrounding the organisms, time-series were selected from the close-up video imagery acquired simultaneously, and only data corresponding to a probe position $\sim 0-2 \mathrm{~cm}$ above the surface of the Alvinella colony were retained. For each biological sample, mean, maximum

191 and minimum temperature were then defined while mean, minimal and maximal values of $192 \mathrm{pH}$, sulphide and iron were calculated from the correlations previously established for each 193 vent.

All biological samples were obtained from Alvinella pompejana colonies, except two

197 of them which corresponded to the collection of Riftia pachyptila clumps. Fauna was

198 collected using the hydraulic arm of the ROV, occasionally completed with the ROV suction 199 device, on an area from $\sim 400$ to $700 \mathrm{~cm}^{2}$. On board, samples were washed on a $1 \mathrm{~mm}$ mesh 200 sieve and fixed with $10 \%$ neutral formalin in seawater. In the laboratory, all gastropods 
201

202

203

204

205

206

207

208

209

210

specimens were sorted, identified to the species level when possible and then transferred to $70^{\circ}$ ethanol.

\section{Analysis of community structure}

Multivariate analyses were performed with the software Primer v.5 in order to group the samples according to their faunal composition using the Bray-Curtis similarity index calculated from standardized and square-root transformed species-abundance data. The initial standardization consists in calculating the relative abundance of each species by dividing each count by the total abundance of all individuals in the sample, and consequently removes any effect due to differences in sample volumes (Clarke \& Warwick, 2001). Data were presented using two complementary graphic approaches: cluster using group-average linking, and nonmetric multi-dimensional scaling (NMDS). For each faunal assemblage, species-effort accumulation curves with $95 \%$ confidence intervals were generated from species-abundance data using EstimateS v.7.5 (Colwell, 2005) to compare biodiversity distribution from samples of very different size.

In order to assess the environment influence on the community structure, faunal data were linked to environmental factors using the BIO-ENV procedure within the Primer program (Clarke \& Ainsworth, 1993). The different steps of this procedure are as follows. A biotic matrix based on Bray-Curtis similarity index from faunal data and abiotic matrices based on the Euclidian distance from environmental factors are established. While the amongsamples similarity matrix was calculated once, the equivalent matrix on abiotic data was computed many times at different levels of complexity (i.e. $k$ variables at a time, where $k=$ $1,2,3 \ldots, \mathrm{n})$. The best matches of biological and environmental matrices at increasing levels of complexity were measured using the Spearman rank correlation coefficient $\left(\rho_{\omega}\right)$. Minimal values of temperature, $\mathrm{S}(-\mathrm{II})$ and $\mathrm{Fe}(\mathrm{II})$, and maximal $\mathrm{pH}$ were excluded from the analysis as 
they were assumed to not be significant for organisms distribution. The natural turbulence of the environment and the difficulties for precise positioning of probes restricted the reliable definition of these extrema at the organism-scale. It can be reasonably assumed that they should represent surrounding seawater conditions, as shown in other vent habitats where background seawater conditions are recovered within a few centimeters from invertebrate aggregations (Johnson et al., 1988; Le Bris et al., 2006b). To ensure that colinearity among the 8 remaining environmental variables (i.e. mean and maximal values of temperature, S(-II) and $\mathrm{Fe}(\mathrm{II})$, and mean and minimal $\mathrm{pH})$ did not affect results, 2 of them which have mutual correlations above 0.75 were excluded from the analysis: minimal $\mathrm{pH}$ and mean temperature.

\section{Population biology of Lepetodrilus elevatus}

The demographic population structure of Lepetodrilus elevatus was analysed for the Genesis site and the Parigo PP-Ph05(1) vent where this species was in sufficient number (i.e. $>100$ individuals). The curvilinear shell length $\left(\mathrm{L}_{\text {curv }}\right)$, defined as the total length from the anterior edge of the shell to the lip of the protoconch, was used as a size index (Sadosky et al., 2002). Measurements were conducted under the 'Image tool' image analysis software (University of Texas, http://www.uthscsa.edu/dig/download/html) with an error fixed at 0.14 mm. All specimens in a sample were measured except for the two very large samples from the collection of Riftia pachyptila clumps for which a random subsample of $\sim 500$ individuals was used. Size-frequency histograms were constructed using a size class of $0.4 \mathrm{~mm}$ according to three criteria (Jollivet et al., 2000) : (1) most size-classes must contain at least 5 individuals; (2) the number of empty adjacent classes must be minimized; and (3) the size-class interval has to be much greater than the error of measurement. Size-frequency distributions were compared among samples using a Kruskall-Wallis multi-sample test (Zar, 1999). 
All previously measured individuals with a curvilinear length $>3 \mathrm{~mm}$ were sexed to determine the sex-ratio which was compared to a theoretical sex-ratio $1: 1$ with a $\chi^{2}$ goodnessof-fit test. Males were identified by the presence of a large penis, modified from the left cephalic tentacle. In addition, sexual maturity of females was assessed from histological examination of gonads (Pendlebury, 2004; Kelly \& Metaxas, 2007). Depending on the sample size, 1 to 11 females per vent were analysed. Body of females stored in $70^{\circ}$ ethanol were removed from their shell, dehydrated in $100^{\circ}$ ethanol for at least 6 hours, cleared in xylene for 6 hours and embedded in paraffin wax in a $70^{\circ} \mathrm{C}$ oven for approximately 12 hours. Individuals were then set in wax blocks and 2 to 3 serial sections of $7 \mu \mathrm{m}$ thickness were obtained with a microtome. Sections were stained using the picro indigo carmin method which stains nucleus in brown and cytoplasm in green (Gabe, 1968). For each female, 14 to 229 oocytes, in which the nuclei were visible, were measured from images captured under a microscope. As packing of the oocytes can severely distort the oocyte shape, Feret diameter was calculated from the measure of the oocyte area using the Lucia software (Laboratory Imaging Ltd.). Intra- and intersample synchrony of female reproductive development was determined using a Kruskall-

Wallis multi-sample test to compare the oocyte size-frequency distributions. When significant differences occurred, a multiple range test using the Dunn-Nemenyi procedure was performed (Zar, 1999).

\section{RESULTS}

\section{Physico-chemical environment}

At the surface of alvinellid colonies, the mean temperature varied from 6 to $32^{\circ} \mathrm{C}$

272 among samples (Table 2). It was globally higher for the Genesis PP12 samples, varying 273 between 25 and $32^{\circ} \mathrm{C}$, and lower for the Parigo samples, ranging between 7 and $12^{\circ} \mathrm{C}$ at PP$274 \mathrm{Ph} 05(1)$, and 15 and $16^{\circ} \mathrm{C}$ at $\mathrm{PP}-\mathrm{Ph05(2).} \mathrm{At} \mathrm{the} \mathrm{Elsa} \mathrm{site,} \mathrm{large} \mathrm{differences} \mathrm{in} \mathrm{mean}$ 
temperature were observed between the samples from the two vents. While it did not exceed $6^{\circ} \mathrm{C}$ at PP-Ph01, it reached 24 and $20^{\circ} \mathrm{C}$ respectively for the 2 samples from PP-Hot 3 . The range of temperature oscillations was highly variable but tended to be wider as the average temperature increased. Thus, for the Genesis PP12 vent, which displayed the highest mean value, the temperature fluctuated between 5 and $69^{\circ} \mathrm{C}$ over a few minutes. Likewise, at the Elsa PP-Hot3 vent, temperature variations could reach $45^{\circ} \mathrm{C}$ whereas they did not exceed $27^{\circ} \mathrm{C}$ for the Parigo site samples. As discussed in Le Bris \& Gaill (2007), such dispersion of temperature data can be easily explained by, both, turbulent mixing of hot fluid and cold seawater above the openings of Alvinella tubes and weak instabilities in the position of the probe within the steep gradients characterizing these habitats. Note that temperature variations recorded in the present study were independent of time series duration $\left(R^{2}=0.0629 ; n=14 ; p\right.$ $=0.3872$ ).

Estimated mean $\mathrm{pH}$ corresponding to samples were lower than regular seawater $\mathrm{pH}$ with acidic to slightly acidic values (i.e. 6.0-6.6) at the Genesis PP12 and Elsa PP-Hot3 vents and near-neutral to alkaline values (i.e.7.4-7.8) at the Parigo site and the Elsa PP-Ph01 vent (Table 2). Estimated mean sulphide concentrations ranged from 164 to $406 \mu$ mol ${ }^{-1}$ with the highest values corresponding to samples of Parigo PP-Ph05(2), Genesis PP12 and Elsa PPHot3 vents. Reflecting temperature variability, large sulphide ranges were defined for each sample (e.g. ranging between 24 and $927 \mu \mathrm{mol} \mathrm{l}^{-1}$ for the sample E3-b). Iron concentrations greatly differed among sites with a large contrast between the Genesis-Parigo sites and the Elsa site. While iron was strongly depleted in the habitat sampled at Genesis (below the level of detection of our in situ analysis method) and displayed only moderate concentration in the environment of Parigo (less than $29 \mu \mathrm{mol} \mathrm{l}^{-1}$ ), this compound reached much higher concentrations at the Elsa PP-Hot 3 vent (between 270 and $339 \mu \mathrm{mol} \mathrm{l}^{-1}$ ). At Elsa PP-Ph01, the estimated average concentration revealed to be low but the large range of iron content 
300 indicated that it could be found punctually at high concentrations. Rather than a iron-depleted

301 fluid such as observed at Genesis, the low mean iron level in this case reflected a weak contribution of the hydrothermal fluid to the environment, on average, as indicated by a low mean temperature.

As compared to the large variability of physico-chemical conditions encountered when considering the whole architecture of the alvinellid aggregation (Le Bris et al., 2005), the variability of physico-chemical parameters was quite low within a vent at the surface of the alvinellid zone. Conversely, substantial variability in habitat physico-chemical conditions could be observed among different vents within a site. As an example, two types of habitat were considered at the Parigo and Elsa sites: one with lower temperature, near neutral $\mathrm{pH}$ and moderate sulphide concentrations (PP-Ph05-1 and PP-Ph01) versus one with higher 311 temperature, slightly acidic $\mathrm{pH}$ and higher sulphide concentrations (PP-Ph05-2 and PP-Hot3). 312 Major differences among sites were due to variations in iron concentrations.

314 temperature, the thermal range in sample P1-e from Parigo site did not differ from 315 neighbouring samples collected in Alvinella colonies on the same vent (Table 2). According

316 to our model assuming that temperature correlation with chemical parameters is conserved at site scale, similar chemical features for these two environments at Parigo were inferred from 318 similar temperatures.

\section{Faunal composition}

A total of 11 gastropod species were identified in the 14 samples (Table 3). Five 322 species (i.e. Lepetodrilus elevatus, L. pustulosus, Nodopelta heminoda, N. subnoda and 
324 of the total number of individuals in each sample. By contrast, only 2 species (i.e.

325 Pachydermia laevis and Hirtopelta hirta) were found in only one sample.

The cluster analysis showing the percentage similarity of faunal composition for each

sample is given on Figure 1A. Samples separated into two well-defined faunal groups. The cluster 1 included all the samples from the Parigo PP-Ph05(1) vent as well as the G2-a sample collected in a Riftia clump and exhibited high internal similarity. It was largely dominated by L. elevatus which accounted for more than $80 \%$ of individuals. The cluster 2 was composed of samples from Genesis-PP12, Parigo PP-Ph05(2) and Elsa vent sites, which displayed a large proportion of peltospirid gastropods (i.e. P. operculata, N. subnoda, N. heminoda). However, the low internal similarity between samples of this cluster, just over $50 \%$, testified of a high heterogeneity of faunal composition. For example, the samples P2-a, E1-a and E3-a were characterized by a high proportion of $P$. operculata (54.5 to $61.8 \%$ of individuals) and the presence of $N$. subnoda (15.2 to $32.7 \%$ of individuals) while the samples G12-a, G12-b, P2-b and E3-b were mainly composed of a mixture of both species of Nodopelta (23.5 to 84.1 $\%$ of individuals) and L. elevatus (8.3 to $47.1 \%$ of individuals). Species-effort curves suggested that habitats related to the group 2, characterized by a large proportion of 340 peltospirids, have higher species richness than habitats related to group 1, largely dominated 341 by L. elevatus (Figure 2). Nevertheless one can note that no species-effort curve had reached 342 the asymptote.

The BIO-ENV procedure provided the best matching of faunal groups to physico-

344 chemical patterns by considering combinations of environmental variables at increasing levels 345 of complexity. When only one variable was considered, mean sulphide concentration 346 appeared to be the most explanatory variable with a $\rho_{\mathrm{w}}$ of 0.373 . The next best variables were 347 mean $\mathrm{pH}\left(\rho_{\mathrm{w}}=0.358\right)$ and maximal temperature $\left(\rho_{\mathrm{w}}=0.233\right)$. The overall optimum 348 combination involved these 3 variables $\left(\rho_{\mathrm{w}}=0.401\right)$. Superimposing these environmental data 
onto the NMDS performed on faunal composition highlighted the influence of these physicochemical variables in shaping gastropod communities (Figure 1B). The cluster 1 was associated with lower sulphide concentrations and maximal temperatures, and a higher $\mathrm{pH}$. In contrast, the cluster 2 tended to be generally associated with higher maximal temperatures and sulphide concentrations and a lower $\mathrm{pH}$. Nevertheless, a large disparity in physico-chemical conditions occurred within this cluster. As an example, the highest and the lowest mean sulphide concentrations reported in the data set (406 and $\left.53 \mu \mathrm{mol} \mathrm{l}^{-1}\right)$ were observed for two samples from this cluster, E3-a and E1-a respectively (Table 2).

The population structure of L. elevatus was analysed on only 8 samples from 3 vents (i.e. Parigo PP-Ph05(1), Genesis PP12, Genesis Hot2) for which individuals were in sufficient number (Figure 3). The curvilinear shell length ranged from 1.09 to $11.27 \mathrm{~mm}$. Sizefrequency distributions were highly variable among samples (Kruskall-Wallis H statistic = 430.61, $\mathrm{df}=7, \mathrm{p}<10^{-3}$ ). Multiple range tests using the Dunn-Nemenyi procedure identified 4 groups of samples: (i) G12-a, (ii) G2-a, (iii) P1-b, P1-c, P1-d and P1-f, and (iv) P1-a and P1-e. These latter samples differed from the other Parigo samples by a higher abundance of larger individuals (> $7 \mathrm{~mm}$ ). Furthermore, the G12-a sample was distinguishable from other samples by a dominance of small individuals. The proportion of individuals $<5 \mathrm{~mm}$ reached $85.8 \%$ in

368 G12-a while it varied between 14.7 and $48.6 \%$ in other samples.

For all samples the sex-ratio did not differ significantly from the theoretical balanced 1:1 sex-ratio ( $\chi^{2}$ goodness-of-fit test; $\left.p>0.05\right)$. In the gonad, oocyte diameter ranged from 7.3

371 to $113.9 \mu \mathrm{m}$. Two types of germinal cells were observed: (1) small oogonies and 372 previtellogenic oocytes with a large nucleus, a basophilic cytoplasm and a size $<40 \mu \mathrm{m}$ and 373 (2) vitellogenic oocytes with a large cytoplasm containing yolk granules and a size $>40 \mu \mathrm{m}$. 
374 Most females exhibited a common pattern in oocyte size distributions with a first major peak

375 of oogonia and previtellogenic oocytes and a second minor peak of vitellogenic oocytes

376 (Figure 4). However, oocyte size-frequency distributions differed significantly at the different

377 spatial scales analysed in this study, suggesting asynchronous reproduction among vents and

378 among females within each vent (Figure 5). Among vents, significant differences in size

379 distributions (Kruskall-Wallis $\mathrm{H}$ statistic $=246.28$, $\mathrm{df}=4, \mathrm{p}<10^{-3}$ ) were mainly due to the

380 individuals from the Genesis PP12 vent which exhibited a smaller mean oocyte size than

381 individuals from the other vents $(\mathrm{p}<0.05)$. This result could be explained by the animal size

382 as the 7 individuals from the Genesis PP12 vent were the smallest individuals analysed in this

383 study (i.e. curvilinear shell length ranging from 3.71 to $5.48 \mu \mathrm{m}$ ) and were mainly

384 characterized by a large dominance of previtellogenic oocytes (Figure 4). Indeed, while there

385 was a significant correlation between the curvilinear shell length and the percentage of

386 vitellogenic oocytes per female when all females were considered $\left(R^{2}=0.2564, n=72, p<\right.$

$38710^{-3}$ ), the correlation became non significant when the individuals from the Genesis PP12 vent

388 site were removed $\left(\mathrm{R}^{2}=0.0578, \mathrm{n}=65, \mathrm{p}=0.054\right)$. Significant differences in oocyte size

389 distributions were also reported among samples within a vent on the example of Parigo PP-

390 Ph05(1) vent (Kruskall-Wallis H statistic $=62.79, \mathrm{df}=5, \mathrm{p}<10^{-3}$ ) and among females within

391 a sample (sample P1-a: Kruskall-Wallis H statistic $=70.97$, df $=10, \mathrm{p}<10^{-3}$; sample P1-d:

392 Kruskall-Wallis H statistic $=51.61, \mathrm{df}=9, \mathrm{p}<10^{-3}$; sample P1-f: Kruskall-Wallis H statistic

$393=150.36, \mathrm{df}=10, \mathrm{p}<10^{-3}$ ). However, multiple range tests using the Dunn-Nemenyi

394 procedure indicated that 54 to $60 \%$ of the females examined in each sample showed no 395 significant difference in oocyte size-frequency distributions. 
At the scale of a biological sample, a large variability of physico-chemical conditions was reported, consistently with the steep chemical gradients already described over scales of centimetres and seconds to hours in hydrothermal habitats (Johnson et al., 1988; Chevaldonné et al., 1991; Sarradin et al., 1998; Le Bris et al., 2005). From this observation it was suggested that animals would occasionally deal with high temperature, high sulphide concentrations and low $\mathrm{pH}$. However, the estimated amplitude of thermal and chemical ranges at the surface of 404 the alvinellid colony where the gastropods are located are still substantially lower than 405 depicted for the general Alvinella pompejana environment (Sarradin et al., 1998; Luther et al., 2001; Le Bris et al., 2003; Le Bris et al., 2005). This is consistent with the synthesis of temperature ranges reported for this environment in Le Bris \& Gaill (2007) that underlined much milder conditions at the surface of the colony than among the tubes of Alvinella spp. that composed the interface between the chimney wall and seawater. Still, close-up video recordings confirmed that organisms sometimes bathed in turbulent shimmering water, where 411 they can alternately experience, in few seconds, conditions that only slightly depart from 412 seawater and conditions with a more significant hydrothermal influence. Considering the 413 similar temperature ranges, no large variation in the range of physico-chemical conditions 414 was expected among samples in the Alvinella habitat, within a single vent, suggesting that the 415 habitat sampled was quite homogeneous. Within a single Alvinella aggregation, Le Bris et al. 416 (2005) highlighted substantial discrepancies at small-scale but they were mostly reported 417 when comparing different microenvironments in the matrix surrounding Alvinella tubes and 418 the interior of the tubes. Comparatively, measurements from the water layer overlying the 419 surface of the colony, where gastropods live, appear more consistent with the conservative 420 mixing model, at least in the vicinity of venting sources (Le Bris et al., 2005). Larger 421 environmental differences were documented among samples from different vents within a 422 site. Thus, at the Parigo and Elsa sites, one vent was characterized by lower temperature and 
sulphide concentrations, and higher $\mathrm{pH}$ than the other one. Among sites, the most significant result in terms of spatial variations in habitat chemistry regarded iron which distinguished the iron-rich Elsa site from the iron-depleted Genesis and Parigo sites. Such variations in the Fe:S ratio which mainly depends on the end-member vent fluid composition have been already highlighted for the $13^{\circ} \mathrm{N} / \mathrm{EPR}$ hydrothermal vent field (Le Bris et al., 2003, Le Bris \& Gaill, 2007).

While thermal conditions are commonly reported to be strongly contrasted in different hydrothermal habitats (Shank et al., 1998; Luther et al., 2001; Le Bris et al., 2003), no difference in temperature was observed between the sole Riftia-dominated sample and Alvinella-dominated samples at Parigo PP-Ph05(1) vent. Again, this is not so surprising considering that the surface of Alvinella tube aggregation displays a much more limited thermal range than the bulk of the colony. The chemical conditions could however be much more contrasted than assumed here between these habitats as the consistency of the temperature correlation with sulphide, iron and $\mathrm{pH}$ may only be valid when comparing alvinellid environments. Large discrepancies in the sulphide-temperature correlation have been observed between alvinellid and Riftia aggregations located less than one meter apart (Le Bris et al., 2006a).

Similarly to environmental conditions, gastropod community structure was mainly similar among samples from a single vent but variable among vents and sites, being either dominated by peltospirids (i.e. Peltospira operculata, Nodopelta heminoda and N. subnoda) at Elsa, Genesis-PP12 and Parigo PP-Ph05(2) or lepetodrilids (i.e. Lepetodrilus elevatus) at Parigo PP-Ph05(1) and Genesis-Hot 2. Nevertheless, within the peltospirids-dominated vents, the relative proportion of $P$. operculata and Nodopelta spp. as well as the abundance of $L$. elevatus could be highly variable among samples. While numerous studies have already highlighted changes in habitat temperature and chemistry as primary driving forces for 
448 changes in hydrothermal community composition at the site or vent field-scale (Sarrazin et 449 al., 1997; Shank et al., 1998; Sarrazin \& Juniper, 1999), our study showed that for gastropods 450 the most explanatory environmental variable considered alone was the mean sulphide 451 concentration followed by the mean $\mathrm{pH}$ and maximal temperature. If the best matching of 452 faunal composition to environment involved these 3 physico-chemical variables, the addition 453 of $\mathrm{pH}$ and temperature improved only slightly the link between environmental data and 454 gastropod distribution patterns.

The role of these 3 environmental variables on species distribution may be related to physiological adaptations and nutritional requirements as generally suggested for hydrothermal fauna. Sulphide is thought to be the primary energy source for chemosynthetic 458 bacterial primary production in these environments (Childress \& Fisher, 1992) but is also 459 known to be deleterious to all aerobic organisms (Visman, 1991). Hydrothermal animals thus 460 have to deal with conflicting constraints related to this compound. Likewise, temperature can 461 act directly on vent fauna according to their thermal tolerance. Lee (2003) experimentally 462 showed that Lepetodrilus fucensis and Depressigyra globulus, 2 common gastropods in 463 alvinellid colonies at the Juan de Fuca Ridge (Northeast Pacific), could not stand short 464 exposure to temperature exceeding $30-35^{\circ} \mathrm{C}$ and $35-40^{\circ} \mathrm{C}$ respectively. Moreover, Bates et al. 465 (2005) suggested from field observations and experiments that temperature had a significant 466 influence on the distribution patterns of 3 gastropod species (i.e. L. fucensis, D. globulus and 467 Provanna variabilis) from the Juan de Fuca Ridge. While the former two species occupied 468 near-vent habitats with a temperature between 5 and $13^{\circ} \mathrm{C}$, the latter one was reported in areas 469 with significantly lower temperature from 4 to $11{ }^{\circ} \mathrm{C}$. Although the direct influence of $\mathrm{pH}$ on 470 vent fauna physiology is less documented, this parameter is highly relevant to assess the 471 impact of habitat condition on vent communities as it mainly affects the distribution of 472 sulphide in different chemical forms of contrasted biological effects (Le Bris et al., 2003). 
473 The sulphide toxicity and bioavailability mostly depends on the relative proportions of the

474 free sulphide and iron-associated forms (Luther et al., 2001; Le Bris et al., 2003). According

475 to their iron concentration and $\mathrm{pH}$ range, the quality of the habitats sampled in this study

476 could be classified in terms of relative toxicity. At low to negligible iron concentrations, free

477 sulphide forms $\left(\mathrm{H}_{2} \mathrm{~S}\right.$ and $\left.\mathrm{HS}^{-}\right)$constitute the dominant sulphide species. The acidity constant

478 (pKa) of $\mathrm{H}_{2} \mathrm{~S}$ being close to 7 , sulphide should be mostly present as the most toxic neutral

479 species, $\mathrm{H}_{2} \mathrm{~S}$, in the higher temperature and more acidic habitat (i.e. Genesis PP-12) while it

480 would be mostly present as the less toxic anionic species, $\mathrm{HS}^{-}$, in the lower temperature and

481 less acidic habitat (i.e. Parigo PP-Ph05(1)). Conversely, the high iron concentrations observed

482 at Elsa site would decrease sulphide environmental toxicity, even in this acidic habitat by the

483 formation of FeS.

484 A first assumption to explain the differential distribution between peltospirids and 485 lepetodrilids species at $13^{\circ} \mathrm{N}$ could be their different thermal tolerance. Such assumption is in accordance with recent observations performed at $9^{\circ} 50^{\prime} \mathrm{N}$ which showed different thermal boundaries between lepetodrilids mainly associated with the vestimentiferan habitat and 488 peltospirids confined to alvinellids habitat (Mills et al., 2007). However, if L. elevatus was 489 abundant (more than $50 \%$ of individuals) in samples with maximal temperature not exceeding $29^{\circ} \mathrm{C}$, it was also reported in samples where maximal temperature reached $69^{\circ} \mathrm{C}$, 491 suggesting that this species could be subject to short-term exposures to high temperature. The 492 better tolerance of Nodopelta spp. and P. operculata to sulphide toxicity, as compared to $L$. 493 elevatus might provide another explanation to the distribution observed. In this case, the

494 former species will be favored in habitats characterized by higher sulphide concentrations and temperature, and more acidic conditions. However, gastropods community structure in the 496 presumably more toxic environment, Genesis-PP12, did not highly differ from the structure 497 reported in samples from sulphide-rich but less toxic environment like Elsa PP-Hot3 and 
498 Parigo PP-Ph05(2) vents. Govenar et al. (2005) also highlighted high similarity in epifaunal community structure including lepetodrilids in Riftia pachyptila clumps of contrasted sulphide and iron ranges

Despite heuristic and conceptual interest, the BIO-ENV procedure mainly remains an exploratory tool to assess the relationship between multivariate community structure and environmental variables (Clarke \& Warwick, 2001). Even if conclusions cannot be supported by significance tests given the lack of model assumptions underlying the procedure, the low values of $\rho_{\mathrm{w}}$ ranging from 0.373 to 0.401 suggested that chemical variables as measured in this study only poorly explained gastropod distribution patterns. Two non-exclusive hypotheses could be proposed: (1) limitations in the ability to discriminate habitats in terms of 508 physico-chemical conditions experienced by organisms and (2) a more complex interplay 509 between abiotic factors impact and biological interactions. Chemical parameters were not measured simultaneously with temperature prior to animal collections, but were extrapolated from temperature measurements assuming a 512 conservative behavior in the mixing interface between the source fluid and ambient seawater 513 at the scale of a single vent edifice. These limitations may have reduced the validity of our 514 extrapolations as some discrepancies in the temperature relationship with chemical factors have been reported at site scale for various types of hydrothermal habitats (Johnson et al., 1988; Le Bris et al., 2000, 2005, 2006b). Indeed, several processes can alter the relationships 517 between temperature and chemical parameters including biological consumption of sulphides 518 in mussel beds and Riftia clumps (Johnson et al., 1994; Le Bris et al., 2006b) and conductive 519 thermal exchanges in Alvinella colonies (Le Bris et al., 2005). Over similar temperature ranges, highly different sulphide contents may indeed characterize adjacent Riftia clumps and 521 Alvinella colonies on a single chimney (Luther et al., 2001; Le Bris et al., 2003, 2006b), and the lack of chemical differences supposed at Parigo PP-Ph05(1) vent between both habitats 
may be erroneous in the present study. In the Alvinella habitat, if temperature is not a relevant tracer of fluid mixing, the processes involved vary among distinct micro-environments (Le Bris et al., 2005). In the inner-tube environment, the unexpected combination of a high temperature and a high $\mathrm{pH}$ is mostly explained by a conductive heating of a seawaterdominated mix through the tube walls whereas, in the medium surrounding the tubes, a conductive cooling of the warm and low $\mathrm{pH}$ fluid occurs when it passes through the thickness of the worm colony. By contrast, at the surface of the colonies, a detailed analysis of the relationship between temperature and $\mathrm{pH}$, considered as a reliable tracer of the vent fluid contribution, suggested that the conservative mixing hypothesis is acceptable in a first approximation (Le Bris et al., 2005). For this peculiar environment on which most of the present study focused, the use of empirical correlations between temperature and chemical parameters could be assumed to have greatly improved the general characterization of habitats, as compared to those only based on temperature measurements. On the other hand, even if close-up video imagery was used to ensure that ranges and mean values described the environment of gastropods at the surface of Alvinella colonies, the measurement strategy used for this study did not allow us to characterize fine-scale temperature variability in microniches at the individual scale (i.e. cm) as reported in Di Meo-Savoie et al. (2004), Bates et al. (2005) and Le Bris et al. (2005). Indeed, some hydrothermal gastropods may occupy microhabitats that differ from the general surrounding physico-chemical environment at the surface of Alvinella colonies (Mills et al., 2007).

A better assessment of temporal variability would be also required to appreciate the factors that could influence species distribution. Temperature in vent habitats fluctuates at different time scales, in response to turbulent mixing of hydrothermal fluid and ambient seawater which produces rapid pulsations and brief spikes at second to minute scales, to tidal motion at hour to day scales, and to variations in bottom currents and hydrothermal emissions 
548 at longer scale (Shank et al., 1998; Chevaldonné et al., 1991; Tivey et al., 2002). In the 549 present study, time series measurements of temperature performed only at short timescale, 550 from about 1 to 44 minutes, could imperfectly describe thermal conditions encountered by 551 organisms. A continuous record of temperature over a week on an A. pompejana colony at 552 Elsa PP-Hot3 vent showed that temperature mostly ranged between 10 and $20^{\circ} \mathrm{C}$ but could 553 display peaks of temperature reaching $25-27^{\circ} \mathrm{C}$ for a duration of several hours (Pradillon et al., 2005a). Nevertheless, measurements carried out at different dates at Parigo PP-Ph05(1) vent in the present study provided comparable range of temperature variations and no significant relationship occurred between temperature fluctuations and time series duration, suggesting some stability over time. Likewise, the Fe:S ratio in end-member fluid which is 558 largely modulated by subsurface processes, was also reported to be highly variable in time in 559 relation to variations in fluid emission, mainly at monthly to yearly scales (Shank et al., 1998; 560 Von Damm \& Lilley, 2004). The distinction between the iron-rich Elsa site and the iron561 depleted Genesis and Parigo sites depicted in the present study has already been mentioned by 562 Le Bris et al. (2003) from measurements performed 3 years before (Le Bris et al., 2003). 563 Thus, for mobile species like gastropods which can actively respond to long-term variations in 564 the physico-chemical environment, we can expect that our data are sufficiently representative 565 of the global range of environmental parameters actually experienced by the organisms at scales ranging at least from minutes to weeks. In addition to the organism physiological tolerances to the physico-chemical 568 environment, the gastropod community structure could also rely on biological interactions 569 between species, including predation and competition for a limiting food and space resource.

570 Over a limited range of environmental conditions, the relative dominance of one species would in part depend on its abilities to outcompete other species according to its reproductive and growth potential. In this context, the most striking result of the present study is the lower 
573 species richness in the lower temperature and sulphide concentrations vent (Parigo PP-

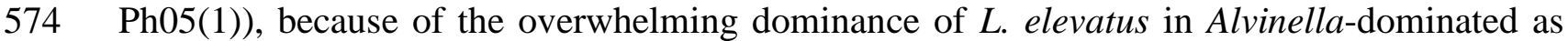
well as Riftia-dominated habitats. In the Riftia habitat, manipulative field-experiments already showed that L. elevatus could strongly modify the community structure, and exert negative influences on sessile and mobile colonists by physically dislodging their recruits (Micheli et 578 al., 2002; Mullineaux et al., 2003). Different results on the demography and reproduction of

579 L. elevatus in relation to physico-chemical conditions may support the hypothesis that this species might well develop in a less extreme environment and influence peltospirid 581 populations.

The significant variation of size-frequency distributions of L. elevatus among vents 583 could result from numerous factors including (i) sampling bias related to small sample size, 584 (ii) spatial and temporal variations in larval supply (Metaxas, 2004), (iii) site- and sizespecific growth rate (Mullineaux et al., 1998) or (iv) site-and size-specific mortality rate.

586 Nevertheless, the main difference was due to the only sample collected in a high temperature 587 and high sulphide toxicity environment at Genesis PP12 vent which differed significantly 588 from all other samples by a very small proportion of large individuals. Furthermore, 589 Mullineaux et al. (1998) or Sadosky et al. (2002) have shown that recruitment of this species 590 is generally coherent at the vent field scale. Thus, even if the factors mentioned above cannot 591 be ruled out, this pattern may suggest that physico-chemical conditions could alter the 592 demography of L. elevatus. The very high proportion of small individuals at Genesis PP12 593 vent may result from broader physiological tolerances and higher survivorship of juveniles 594 than adults in marginal habitat as already reported by Mullineaux et al. (1998). In terms of 595 reproduction, heterogeneous size-frequency distributions of oocytes among mature females 596 confirmed that gametogenesis was asynchronous at vent as well as at sample scale 597 (Pendlebury, 2004), and seemed independent of the physico-chemical environment. However, 
598 the positive relationship between the animal size and its sexual maturity, defined as the 599 proportion of vitellogenic oocytes, indicated that most individuals from the Genesis PP12 600 vent were immature and did not participate to the local reproductive effort. Along the Juan de 601 Fuca Ridge, Kelly \& Metaxas (2007) observed that L. fucensis gametogenic maturity did not 602 vary between actively venting habitats but was significant lower in senescent areas according 603 to variation in energy supply. Here, while the environment at the Genesis site may constitute 604 the upper limit for L. elevatus to develop, the cooler habitats seem to be optimal, so that the 605 females can maximize their reproductive output. While the lack of replicate in the most toxic 606 habitat impedes a global statistical analysis over the range of physico-chemical conditions 607 encountered in the present study, those results suggest that L. elevatus may be highly 608 competitive in the lower temperature and less toxic environmental conditions. Even if 609 peltospirid gastropods may probably survive in lower temperature, as at Elsa PP-Ph01 vent, 610 habitat colonization by L. elevatus could exclude them since environmental conditions are 611 favorable to the development of this latter species in Alvinella- as well as in Riftia-dominated 612 habitat.

613 In describing the different hydrothermal communities structure and diversity patterns, 614 only a few studies to date have included locally defined chemical parameters of ecological 615 relevance to identify processes governing the observed patterns (Sarrazin et al., 1997; Shank 616 et al., 1998; Sarrazin \& Juniper, 1999; Govenar et al., 2005). Despite the inabilities to actually 617 perform quantitative samples in the high-temperature hydrothermal environment, the present 618 study reported for the first time the influence of environmental chemistry on epifaunal 619 assemblages in different alvinellid colonies at vents along the East Pacific Rise, focusing on 620 gastropods. The main physico-chemical parameters governing the habitat quality and 621 consequently the community structure were, in a decreasing order of importance, mean 622 sulphide concentration, mean $\mathrm{pH}$ and maximal temperature. Peltospirid gastropods (i.e. 
623 Nodopelta spp. and P. operculata) were then dominant in the more acidic, higher temperature 624 and richer sulphide vents than lepetodrilid gastropods (i.e. Lepetodrilus elevatus) (Figure 6). 625 Although this pattern could result from different specific physiological tolerances and

626 nutritional requirements, the occurrence of all common species over a wide range of physico-

627 chemical conditions as well as the low correlation between biological community structure 628 and physico-chemical parameters suggests that other factors may be responsible for 629 community composition in Alvinella colonies. In particular, the lower richness resulting from 630 the dominance of L. elevatus in the lower temperature and sulphide concentrations habitat 631 suggests that the later species may outcompete other species in such environmental 632 conditions. Thus, in these conditions, gastropod community structure did not differ between 633 Alvinella colonies and Riftia clumps. If field samples remain essential to describe patterns and 634 make assumptions about processes involved, further experimental manipulative shipboard and 635 field studies should be necessary to identify the ways of biogeochemical processes on 636 community structure and separate unambiguously the relative contributions of physiological 637 tolerance, nutritional requirement and biological interactions.

640 We thank the captain and crew of the NO L'Atalante and the team of the ROV Victor 6000 641 for their helpful collaboration at sea. We also acknowledge P.-M. Sarradin, C. Le Divenah, C. 642 Le Gall and P. Rodier for their support in the implementation of in situ chemical analysis and 643 collection devices. We are grateful to S. Hourdez for the English proof reading and to two 644 anonymous referees for their valuable comments on a first draft of the manuscript. This work 645 was financially supported by Ifremer and the French Dorsales program (INSU, Ifremer, 646 CNRS). It is also a contribution to the GDR Ecchis and the ANR 'Deep Oases' project (ANR647 06-BDIV-005). 
651 Bates, A.E., Tunnicliffe, V. \& Lee, R.W., 2005. Role of thermal conditions in habitat selection by hydrothermal vent gastropods. Marine Ecology Progress Series, 305, 1-15.

Chevaldonné, P., Desbruyères, D. \& Le Haître, M., 1991. Time-series of temperature from three deep-sea hydrothermal vent sites. Deep Sea Research Part I, 38, 1417-1430.

Childress, J.J. \& Fisher, C.R., 1992. The biology of hydrothermal vent animals: physiology, biogeochemistry, and autotrophic symbioses. Oceanography and Marine Biology. An Annual Review, 30, 31-104.

Clarke, K.R. \& Ainsworth, M., 1993. A method of linking multivariate community structure to environmental variables. Marine Ecology Progress Series, 92, 205-219.

Clarke, K.R. \& Warwick, R.M., 2001. Change in marine communities: an approach to statistical analysis and interpretation, 2nd edn PRIMER-E Ltd. Plymouth, UK.

Colwell, R.K., 2005. EstimateS v7.5. Statistical estimation of species richness and shared species from samples. User's guide. http://viceroy.eeb.uconn.edu/estimates

Copley, J.T.P., Tyler, P.A., Van Dover, C.L. \& Philip, S.J., 2003. Spatial variation in the reproductive biology of Paralvinella palmiformis (Polychaeta: Alvinellidae) from vent field on the Juan de Fuca Ridge. Marine Ecology Progress Series, 255, 171-181.

Desbruyères, D., Chevaldonné, P., Alayse-Danet, A.-M., Jollivet, D., Lallier, F., JouinToulmond, C., Zal, F., Sarradin, P.-M., Cosson, R., Caprais, J.-C., Arndt, C., O'Brien, J., Biology and ecology of the "Pompeii worm" (Alvinella pompejana Desbruyères and Laubier), a normal dweller of an extreme deep-sea environment: a synthesis of current knowledge and recent developments. Deep Sea Research Part II, 45, 383-422. 
673 Di Meo-Savoie, C.A., Luther, G.W. \& Cary, S.C., 2004. Physicochemical characterization of 674 the microhabitat of the epibionts associated with Alvinella pompejana, a hydrothermal vent annelid. Geochimica et Cosmochimica Acta, 68, 2055-2066.

676 Dreyer, J.C., Knick, K.E., Flickinger, W.B. \& Van Dover, C.L., 2005. Development of 677 macrofaunal community structure in mussel beds on the northern East Pacific Rise. $678 \quad$ Marine Ecology Progress Series, 302, 121-134.

679 Gabe, M., 1968. Techniques histologiques, Paris: Masson

680 Govenar, B.W., Freeman, M., Bergquist, D.C., Johnson, G.A. \& Fisher, C.R., 2004.

681 Composition of a one-year-old Riftia pachyptila community following a clearance 682 experiment: insight to succession patterns at deep-sea hydrothermal vents. Biological $683 \quad$ Bulletin, 207, 177-182.

684 Govenar, B.W., Le Bris, N., Gollner, S., Glanville, J., Aperghis, A.B., Hourdez, S. \& Fisher, 685 C.R., 2005. Epifaunal community structure associated with Riftia pachyptila aggregations 686 in chemically different hydrothermal vent habitats. Marine Ecology Progress Series, 305, $687 \quad 67-77$.

688 Johnson, K.S., Childress, J.J., Beehler, C.L. \& Sakamoto-Arnold, C.M., 1994. 689 Biogeochemistry of hydrothermal vent mussel communities: the deep-sea analogue to the 690 intertidal zone. Deep Sea Research Part I, 41, 993-1011.

691 Johnson, K.S., Childress, J.J., Hessler, R.R., Sakamoto-Arnold, C.M. \& Beehler, C.L., 1988.

692 Chemical and biological interactions in the Rose Garden hydrothermal vent field, 693 Galapagos spreading center. Deep Sea Research Part II, 35, 1723-1744.

694 Jollivet, D., 1996. Specific and genetic diversity at deep-sea hydrothermal vents: an overview. 695 Biodiversity and Conservation, 5, 1619-1653.

696 Jollivet, D., Empis, A., Baker, M.C., Hourdez, S., Comtet, T., Jouin-Toulmond, C., 697 Desbruyères, D. \& Tyler, P.A., 2000. Reproductive biology, sexual dimorphism, and 
population structure of the deep-sea hydrothermal vent scale-worm, Branchipolynoe seepensis (Polychaeta: Polynoidae). Journal of the Marine Biological Association of the United Kingdom, 80, 55-68.

701

702

703

704

705

706

707

708

709

710

711

712

713

714

715

716

Kelly, N.E. \& Metaxas, A., 2007. Influence of habitat on the reproductive biology of the deep-sea hydrothermal vent limpet Lepetodrilus fucensis (Vetigastropoda: Mollusca) from the Northeast Pacific. Marine Biology, 151, 649-662.

Le Bris, N. \& Gaill, F., 2007. How does the annelid Alvinella pompejana deal with an extreme hydrothermal environment? Reviews in Environmental Science and Biotechnology, 6, 197-221.

Le Bris, N., Govenar, B., Le Gall, C., Fisher, C.R., 2006a. Variability of physico-chemical conditions in $9^{\circ} 50$ 'N EPR diffuse flow vent habitats. Marine Chemistry, 98, 167-182.

Le Bris, N., Rodier, P., Sarradin, P.-M. \& Le Gall, C., 2006b. Is temperature a good proxy for sulfide in hydrothermal vent habitats? Cahiers de Biologie Marine, 47, 465-470.

Le Bris, N., Sarradin, P.-M., Birot, D. \& Alayse-Danet, A.-M., 2000. A new chemical analyzer for in situ measurement of nitrate and total sulfide over hydrothermal vent biological communities. Marine Chemistry, 72, 1-15.

Le Bris, N., Sarradin, P.-M. \& Caprais, J.-C., 2003. Contrasted sulphide chemistries in the environment of $13^{\circ} \mathrm{N}$ EPR vent fauna. Deep Sea Research Part I, 50, 737-747.

Le Bris, N., Sarradin, P.-M. \& Pennec, S., 2001. A new deep-sea probe for in situ pH measurement in the environment of hydrothermal vent biological communities. Deep Sea Research Part I, 48, 1941-1951.

Le Bris, N., Zbinden, M. \& Gaill, F., 2005. Processes controlling the physico-chemical microenvironments associated with Pompeii worms. Deep Sea Research Part I, 52, 1085-1092.

Lee, R.W., 2003. Thermal tolerance of deep-sea hydrothermal vent animals from the northeast Pacific. Biological Bulletin, 205, 98-101. 
Luther, G.W., Rozan, T.F., Martial, T., Nuzzio, D.B., Di Meo, C., Shank, T.M., Lutz, R.A. \& Cary, S.C., 2001. Chemical speciation drives hydrothermal vent ecology. Nature, 410, 813-816.

Metaxas, A., 2004. Spatial and temporal patterns in larval supply at hydrothermal vents in the northeast Pacific ocean. Limnology and Oceanography, 49, 1949-1956.

Micheli, F., Peterson, C.H., Mullineaux, L.S., Fisher, C.R., Mills, S.W., Sancho, G., Johnson, G.A. \& Lenihan, H.S., 2002. Predation structures communities at deep-sea hydrothermal vents. Ecological Monographs, 72, 365-382.

Mills, S.W., Mullineaux, L.S. \& Tyler, P.A., 2007. Habitat associations in gastropod species at East Pacific Rise hydrothermal vents (950'N). Biological Bulletin, 212, 185-194.

Mullineaux, L.S., Fisher, C.R., Peterson, C.H. \& Schaeffer, S.W., 2000. Tubeworm succession at hydrothermal vents: use of biogenic cues to reduce habitat selection error? Oecologia, 123, 275-284.

Mullineaux, L.S., Mills, S.W. \& Goldman, E., 1998. Recruitment variation during a pilot colonization study of hydrothermal vents $\left(9^{\circ} 50^{\prime}\right.$ N, East Pacific Rise). Deep Sea Research Part II, 45, 441-464.

Mullineaux, L.S., Peterson, C.H., Micheli, F. \& Mills, S.W., 2003. Successional mechanism varies along a gradient in hydrothermal fluid flux at deep-sea vents. Ecological Monographs, 73, 523-542.

Pendlebury, S.J.D., 2004. Ecology of hydrothermal vent gastropods. $\mathrm{PhD}$ thesis, University of Southampton, School of Ocean and Earth Science, Southampton, UK.

Pradillon, F., Le Bris, N., Shillito, B., Young, C.M. \& Gaill, F., 2005a. Influence of environmental conditions on early developement of the hydrothermal vent polychaete Alvinella pompejana. Journal of Experimental Biology, 208, 1551-1561. 
747 Pradillon, F., Zbinden, M., Mullineaux, L.S. \& Gaill, F., 2005b. Colonisation of newlyopened habitat by a pioneer species, Alvinella pompejana (Polychaeta: Alvinellidae), at East Pacific Rise vent sites. Marine Ecology Progress Series, 302, 147-157.

Sadosky, F., Thiébaut, E., Jollivet, D. \& Shillito, B., 2002. Recruitment and population structure of the vetigastropod Lepetodrilus elevatus at $13^{\circ} \mathrm{N}$ hydrothermal vent sites on East Pacific Rise. Cahiers de Biologie Marine, 43, 399-402.

Sarradin, P.-M., Caprais, J.-C., Briand, P., Gaill, F., Shillito, B. \& Desbruyères, D., 1998. Chemical and thermal description of the environment of the Genesis hydrothermal vent community (13º N, EPR). Cahier de Biologie Marine, 39, 159-167.

Sarrazin, J. \& Juniper, S.K., 1999. Biological characteristics of a hydrothermal edifice mosaic community. Marine Ecology Progress Series, 185, 1-19.

Sarrazin, J., Robigou, V., Juniper, S.K. \& Delaney, J.R., 1997. Biological and geological dynamics over four years on a high-temperature sulfide structure at the Juan de Fuca Ridge hydrothermal observatory. Marine Ecology Progress Series, 153, 5-24.

Shank, T.M., Fornari, D.J., Von Damm, K.L., Lilley, M.D., Haymon, R.M. \& Lutz, R.A., 465-515.

Taylor, C.D., Wirsen, C.O. \& Gaill, F., 1999. Rapid microbial production in filamentous sulfur mats at hydrothermal vents. Applied and Environmental Microbiology, 35, 22532255.

Tivey, M.K., Bradleyb, A.M., Joyce, T.M. \& Kadkod, D., 2002. Insights into tide-related variability at seafloor hydrothermal vents from time-series temperature measurements. Earth and Planetary Science Letters, 202, 693-707. 
771 Tsurimi, M. \& Tunnicliffe, V., 2003. Tubeworm-associated communities at hydrothermal

772 vents on the Juan de Fuca Ridge, northeast Pacific. Deep Sea Research Part I, 50, 611$773 \quad 629$.

774 Van Dover, C.L., 2003. Variation in community srtucture within hydrothermal vent mussel 775 beds of the East Pacific Rise. Marine Ecology Progress Series, 253, 55-66.

776 Visman, B., 1991. Sulfide tolerance: physiological mechanisms and ecological implications. $777 \quad$ Ophelia, 34, 1-27.

778 Von Damm, K. \& Lilley, M.D., 2004. Diffuse flow hydrothermal fluids from 950'N East 779 Pacific Rise: origin, evolution, and biogeochemical controls. In The subseafloor biosphere 780 at Mid-Ocean Ridges (eds. W.S.D. Wilcock, E.F. DeLong, D.S. Kelley, J.A Baross \& 781 S.C. Cary), pp. 243-266. Washington: American Geophysical Union.

782 Zar, J.H., 1999. Biostatistical analysis, $4^{\text {th }}$ edn. Upper Saddle River: Prentice Hall. 
Table 1. Location of the study sites and biological samples. For each sample, the number of temperature sampling points and the duration of temperature measurements used to characterize the physico-chemical habitat are given. * indicates samples collected in Riftia clumps.

\begin{tabular}{|c|c|c|c|c|c|c|c|}
\hline Vent site & Vent & Sample & Latitude & Longitude & Date (2002) & $\begin{array}{c}\text { Number of } \\
\text { temperature } \\
\text { sampling points }\end{array}$ & $\begin{array}{c}\text { Total duration of } \\
\text { temperature } \\
\text { measurements (min:s) }\end{array}$ \\
\hline \multirow[t]{3}{*}{ Genesis } & PP12 & $\overline{G 12-a}$ & $12^{\circ} 48,632^{\prime} \mathrm{N}$ & $103^{\circ} 56,426^{\prime} \mathrm{W}$ & May 25 & 3 & $1: 01$ \\
\hline & & G12-b & & & May 25 & 5 & $6: 44$ \\
\hline & Hot2 & $\mathrm{G} 2-\mathrm{a}^{*}$ & $12^{\circ} 48,635^{\prime} \mathrm{N}$ & $103^{\circ} 56,404^{\prime} \mathrm{W}$ & May 30 & 4 & $49: 18$ \\
\hline \multirow[t]{8}{*}{ Parigo } & PP-Ph05(1) & $\mathrm{P} 1-\mathrm{a}$ & $12^{\circ} 48,585^{\prime} \mathrm{N}$ & $103^{\circ} 56,400^{\prime} \mathrm{W}$ & May 19 & 4 & $4: 53$ \\
\hline & & P1-b & & & May 20 & 4 & $42: 41$ \\
\hline & & P1-c & & & May 22 & 2 & $8: 37$ \\
\hline & & P1-d & & & May 22 & 1 & $1: 46$ \\
\hline & & P1-e* & & & May 22 & 4 & $17: 22$ \\
\hline & & P1-f & & & May 23 & 5 & $43: 38$ \\
\hline & PP-Ph05(2) & $\mathrm{P} 2-\mathrm{a}$ & $12^{\circ} 48,620^{\prime} \mathrm{N}$ & $103^{\circ} 56,390^{\prime} \mathrm{W}$ & May 30 & 2 & $22: 41$ \\
\hline & & $\mathrm{P} 2-\mathrm{b}$ & & & May 30 & 1 & $9: 42$ \\
\hline \multirow[t]{3}{*}{ Elsa } & PP-Ph01 & E1-a & $12^{\circ} 48,150^{\prime} \mathrm{N}$ & $103^{\circ} 56,267^{\prime} \mathrm{W}$ & May 29 & 4 & $26: 31$ \\
\hline & PP-Hot3 & E3-a & $12^{\circ} 48,145^{\prime} \mathrm{N}$ & $103^{\circ} 56,266^{\prime} \mathrm{W}$ & May 29 & 3 & $6: 56$ \\
\hline & & E3-b & & & May 29 & 5 & $11: 53$ \\
\hline
\end{tabular}


Table 2. Temperature (mean $\pm S D$ ) and chemical parameters (mean) of the different samples from the $13^{\circ} \mathrm{N} / \mathrm{EPR}$ hydrothermal vent field. Range values are given in brackets. For each sample, temperature was measured at different sampling points (see Table 1) while chemical parameters were calculated from geochemical modelling. See text for explanation. nd: not determined. * indicates samples collected in Riftia clumps.

\begin{tabular}{|c|c|c|c|c|c|c|c|c|c|c|c|c|c|c|}
\hline \multirow{3}{*}{$\begin{array}{l}\text { Vent site } \\
\text { Site } \\
\text { Sample }\end{array}$} & \multicolumn{3}{|c|}{ GENESIS } & \multicolumn{8}{|c|}{ PARIGO } & \multicolumn{3}{|c|}{ ELSA } \\
\hline & \multicolumn{2}{|c|}{ PP12 } & \multirow{2}{*}{$\frac{\text { Hot } 2}{\text { G2-a* }}$} & \multicolumn{6}{|c|}{ PP-Ph05(1) } & \multicolumn{2}{|c|}{ PP-Ph05(2) } & \multirow{2}{*}{$\frac{\mathrm{PP}-\mathrm{Ph01}}{\mathrm{E} 1-\mathrm{a}}$} & \multicolumn{2}{|c|}{ PP-Hot3 } \\
\hline & G12-a & G12-b & & $\mathrm{P} 1-\mathrm{a}$ & P1-b & P1-c & P1-d & P1-e* & P1-f & $\mathrm{P} 2-\mathrm{a}$ & P2-b & & E3-a & E3-b \\
\hline $\begin{array}{l}\text { Temperature } \\
\left({ }^{\circ} \mathrm{C}\right)\end{array}$ & $\begin{array}{c}32.3 \pm 11.2 \\
(22.0-48.0)\end{array}$ & $\begin{array}{l}25.4 \pm 19.8 \\
(5.0-69.0)\end{array}$ & $\begin{array}{l}4.9 \pm 1.20 \\
(2.5-7.9)\end{array}$ & $\begin{array}{c}12.4 \pm 3.7 \\
(2.7-18.1)\end{array}$ & $\begin{array}{c}9.5 \pm 2.3 \\
(2.7- \\
18.1)\end{array}$ & $\begin{array}{c}7.3 \pm 1.8 \\
(3.7- \\
12.2)\end{array}$ & $\begin{array}{c}7.1 \pm 0.9 \\
(5.2-8.5)\end{array}$ & $\begin{array}{c}8.0 \pm 3.7 \\
(2.8- \\
16.1)\end{array}$ & $\begin{array}{c}11.2 \pm 6.5 \\
(2.0-29.0)\end{array}$ & $\begin{array}{r}16.0 \pm 4.0 \\
(7.0-25.0)\end{array}$ & $\begin{array}{c}15.0 \pm 3.0 \\
(7.0-20.0)\end{array}$ & $\begin{array}{c}6.2 \pm 2.3 \\
(2.0- \\
22.0)\end{array}$ & $\begin{array}{l}23.8 \pm 12.6 \\
(5.5-50.3)\end{array}$ & $\begin{array}{l}20.4 \pm 12.9 \\
(4.4-50.3)\end{array}$ \\
\hline $\mathrm{pH}$ & $\begin{array}{c}6.0 \\
(5.8-6.2)\end{array}$ & $\begin{array}{c}6.1 \\
(5.5-7.1)\end{array}$ & nd & $\begin{array}{c}7.5 \\
(7.2-8.0)\end{array}$ & $\begin{array}{c}7.5 \\
(7.2-8.0)\end{array}$ & $\begin{array}{c}7.8 \\
(7.5-7.9)\end{array}$ & $\begin{array}{c}7.8 \\
(7.7-7.9)\end{array}$ & $\begin{array}{c}7.7 \\
(7.3-8.0)\end{array}$ & $\begin{array}{c}7.6 \\
(6.4-8.0)\end{array}$ & $\begin{array}{c}7.4 \\
(6.8-7.8)\end{array}$ & $\begin{array}{c}7.4 \\
(7.1-7.8)\end{array}$ & $\begin{array}{c}7.4 \\
(6.7-8.0)\end{array}$ & $\begin{array}{c}6.5 \\
(6.0-7.5)\end{array}$ & $\begin{array}{c}6.6 \\
(6.0-7.7)\end{array}$ \\
\hline S-II $\left(\mu \mathrm{mol} .1^{-1}\right)$ & $\begin{array}{c}394 \\
(263-594)\end{array}$ & $\begin{array}{c}306 \\
(46-861)\end{array}$ & nd & $\begin{array}{c}315 \\
(39-477)\end{array}$ & $\begin{array}{c}234 \\
(39-477)\end{array}$ & $\begin{array}{c}169 \\
(68-310)\end{array}$ & $\begin{array}{c}164 \\
(111- \\
204)\end{array}$ & $\begin{array}{c}191 \\
(42-421)\end{array}$ & $\begin{array}{c}282 \\
(20-788)\end{array}$ & $\begin{array}{c}404 \\
(167-667)\end{array}$ & $\begin{array}{c}385 \\
(156-534)\end{array}$ & $\begin{array}{c}53 \\
(0-600)\end{array}$ & $\begin{array}{c}406 \\
(45-927)\end{array}$ & $\begin{array}{c}339 \\
(24-927)\end{array}$ \\
\hline $\mathrm{Fe}$ II $\left(\mu \mathrm{mol} .1^{-1}\right)$ & 0 & 0 & nd & $\begin{array}{c}22 \\
(0-35)\end{array}$ & $\begin{array}{c}15 \\
(0-35)\end{array}$ & $\begin{array}{c}9 \\
(0-21)\end{array}$ & $\begin{array}{c}9 \\
(4-12)\end{array}$ & $\begin{array}{c}11 \\
(0-31)\end{array}$ & $\begin{array}{c}19 \\
(0-62)\end{array}$ & $\begin{array}{c}29 \\
(9-52)\end{array}$ & $\begin{array}{c}28 \\
(8-40)\end{array}$ & $\begin{array}{c}6 \\
(0-581)\end{array}$ & $\begin{array}{c}339 \\
(0-867)\end{array}$ & $\begin{array}{c}270 \\
(0-867)\end{array}$ \\
\hline
\end{tabular}


Table 3. Number of individuals $(N)$, species richness (SR) and species-abundance list of gastropods collected in the different samples from the $13^{\circ}$ N/EPR hydrothermal vent field. * indicates samples collected in Riftia clumps.

\begin{tabular}{|c|c|c|c|c|c|c|c|c|c|c|c|c|c|c|}
\hline \multirow{3}{*}{$\begin{array}{l}\text { Vent site } \\
\text { Vent } \\
\text { Sample }\end{array}$} & \multicolumn{3}{|c|}{ GENESIS } & \multicolumn{8}{|c|}{ PARIGO } & \multicolumn{3}{|c|}{ ELSA } \\
\hline & \multicolumn{2}{|c|}{ PP12 } & \multirow{2}{*}{$\frac{\text { Hot } 2}{\text { G2-a* }}$} & \multicolumn{6}{|c|}{ PP-Ph05 (1) } & \multicolumn{2}{|c|}{ PP-Ph05 (2) } & \multirow{2}{*}{$\begin{array}{c}\text { PP-Ph01 } \\
\text { E1-a }\end{array}$} & \multicolumn{2}{|c|}{ PP-Hot3 } \\
\hline & G12-a & G12-b & & $\mathrm{P} 1-\mathrm{a}$ & P1-b & P1-c & P1-d & P1-e* & P1-f & $\mathrm{P} 2-\mathrm{a}$ & P2-b & & E3-a & E3-b \\
\hline $\bar{N}$ & 348 & 157 & 10,848 & 164 & 129 & 281 & 250 & 8,258 & 522 & 27 & 17 & 55 & 33 & 91 \\
\hline SR & 8 & 9 & 6 & 4 & 6 & 5 & 6 & 3 & 2 & 5 & 3 & 4 & 8 & 8 \\
\hline Lepetodrilus elevatus & 149 & 13 & 10,589 & 158 & 106 & 250 & 224 & 8,179 & 509 & 2 & 8 & 0 & 4 & 33 \\
\hline Lepetodrilus pustulosus & 4 & 1 & 205 & 3 & 2 & 9 & 12 & 76 & 13 & 0 & 0 & 0 & 1 & 1 \\
\hline Lepetodrilus cristatus & 0 & 1 & 13 & 0 & 1 & 0 & 0 & 0 & 0 & 0 & 0 & 1 & 1 & 7 \\
\hline Nodopelta subnoda & 89 & 68 & 0 & 0 & 7 & 2 & 2 & 0 & 0 & 5 & 0 & 18 & 5 & 22 \\
\hline Nodopelta heminoda & 74 & 64 & 0 & 1 & 8 & 18 & 6 & 0 & 0 & 2 & 4 & 2 & 1 & 22 \\
\hline Peltospira operculata & 27 & 7 & 0 & 2 & 5 & 2 & 5 & 3 & 0 & 15 & 5 & 34 & 18 & 2 \\
\hline Peltospira delicata & 1 & 1 & 1 & 0 & 0 & 0 & 0 & 0 & 0 & 3 & 0 & 0 & 2 & 2 \\
\hline Cyathermia naticoides & 2 & 0 & 11 & 0 & 0 & 0 & 1 & 0 & 0 & 0 & 0 & 0 & 1 & 2 \\
\hline Pachydermia laevis & 2 & 0 & 0 & 0 & 0 & 0 & 0 & 0 & 0 & 0 & 0 & 0 & 0 & 0 \\
\hline Hirtopelta hirta & 0 & 2 & 0 & 0 & 0 & 0 & 0 & 0 & 0 & 0 & 0 & 0 & 0 & 0 \\
\hline Rhynchopelta concentrica & 0 & 1 & 28 & 0 & 0 & 0 & 0 & 0 & 0 & 0 & 0 & 0 & 0 & 0 \\
\hline
\end{tabular}




\section{Figure captions}

Figure 1. Bray-Curtis similarity among the 14 gastropod samples collected in Alvinella colonies and Riftia_clumps at $13^{\circ} \mathrm{N} / \mathrm{EPR}$ hydrothermal vent field. Abundance data were standardised to number of individuals in the sample and square-root transformed. (A) Group average sorting dendrogram. (B) Non-metric Multidimensional Scaling (NMDS). Relationships between the 2 major faunal groups identified by the cluster analysis and physico-chemical variables were reported on the NMDS plots. Size of the bubbles is proportional to the value of the physico-chemical parameters for each sample (see Table 2). * on the group average sorting dendrogram indicates samples collected in Riftia clumps.

Figure 2. Species-effort curves with $95 \%$ confidence intervals generated with the EstimateS v.7.5. software from species abundance data of each faunal assemblage identified by the group average sorting dendrogram. These curves provide an estimate of expected species richness for random subsets sampled in the total species pool of a faunal assemblage.

Figure 3. Size-frequency distributions of the curvilinear shell length of Lepetodrilus elevatus for different samples collected in Alvinella colonies and Riftia clumps from the $13^{\circ} \mathrm{N} / \mathrm{EPR}$ hydrothermal vent field. $\mathrm{N}=$ number of measured individuals. $*$ indicates samples collected in Riftia clumps.

Figure 4. Oocyte size-frequency distributions for Lepetodrilus elevatus from different vents and sizes. L: curvilinear shell length; $\mathrm{N}=$ number of measured oocytes.

Figure 5. Mean oocyte Feret diameter ( $\pm 95 \%$ confidence limits $)(\mu \mathrm{m})$ of Lepetodrilus elevatus at different spatial scales. A, between vents. B, between samples from the Parigo PP- 
Ph05(1) vent. C, D and E, between females from samples P1-a, P1-d and P1-f respectively. Numbers near the mean give the number of individuals and measured oocytes respectively used to calculate mean oocyte diameter. Similar letters indicate no statistical difference among oocyte size distributions $(\mathrm{p}>0.05)$ calculated from the multiple range test using the Dunn-Nemenyi procedure. * indicates samples collected in Riftia clumps.

Figure 6. Schematic representation of the influence of physico-chemical variables on the gastropod community structure for the different vents from the $13^{\circ} \mathrm{N} / \mathrm{EPR}$ hydrothermal vent field. Toxicity of the different habitats was determined from the interactions between total sulphide concentrations, $\mathrm{pH}$, and iron concentrations. For each habitat, dominant gastropod species are indicated. 
39

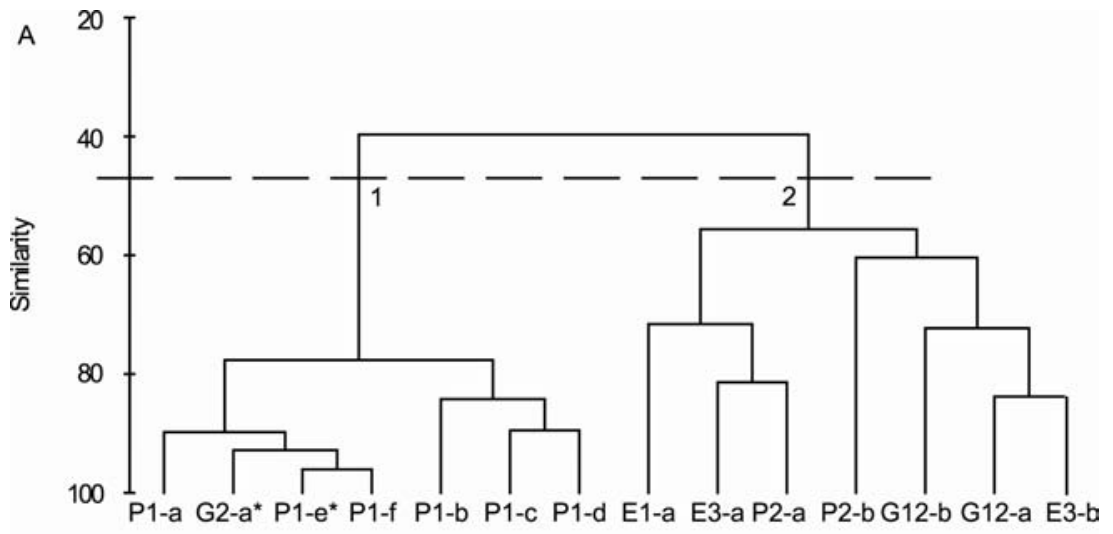

B
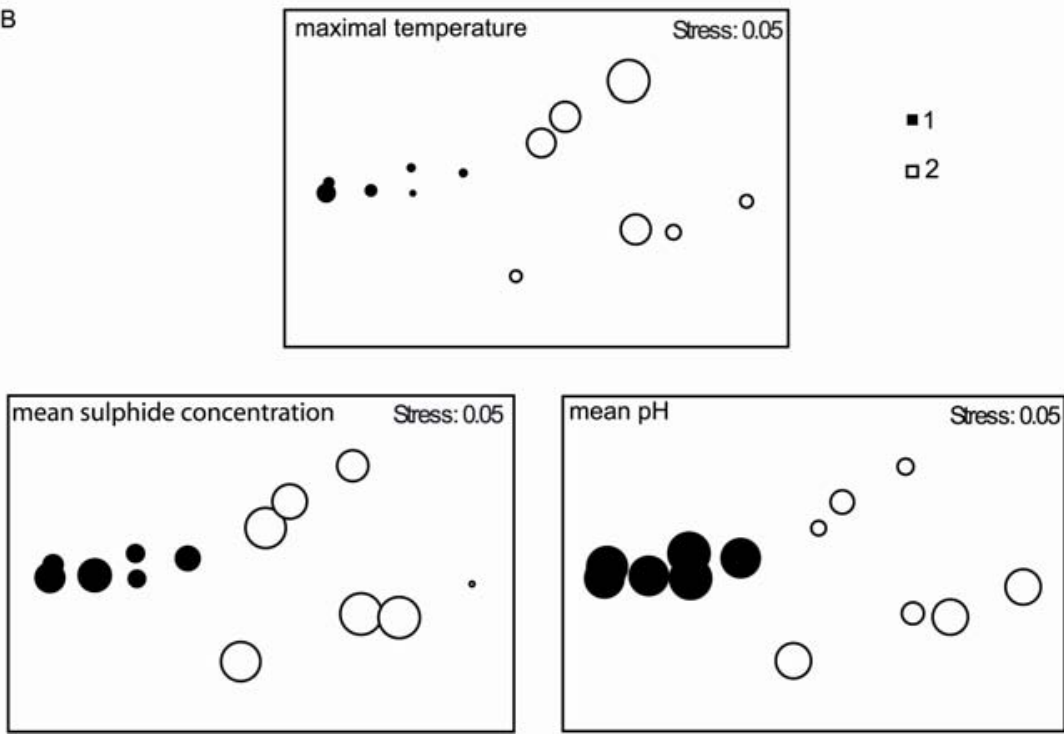

Figure 1 


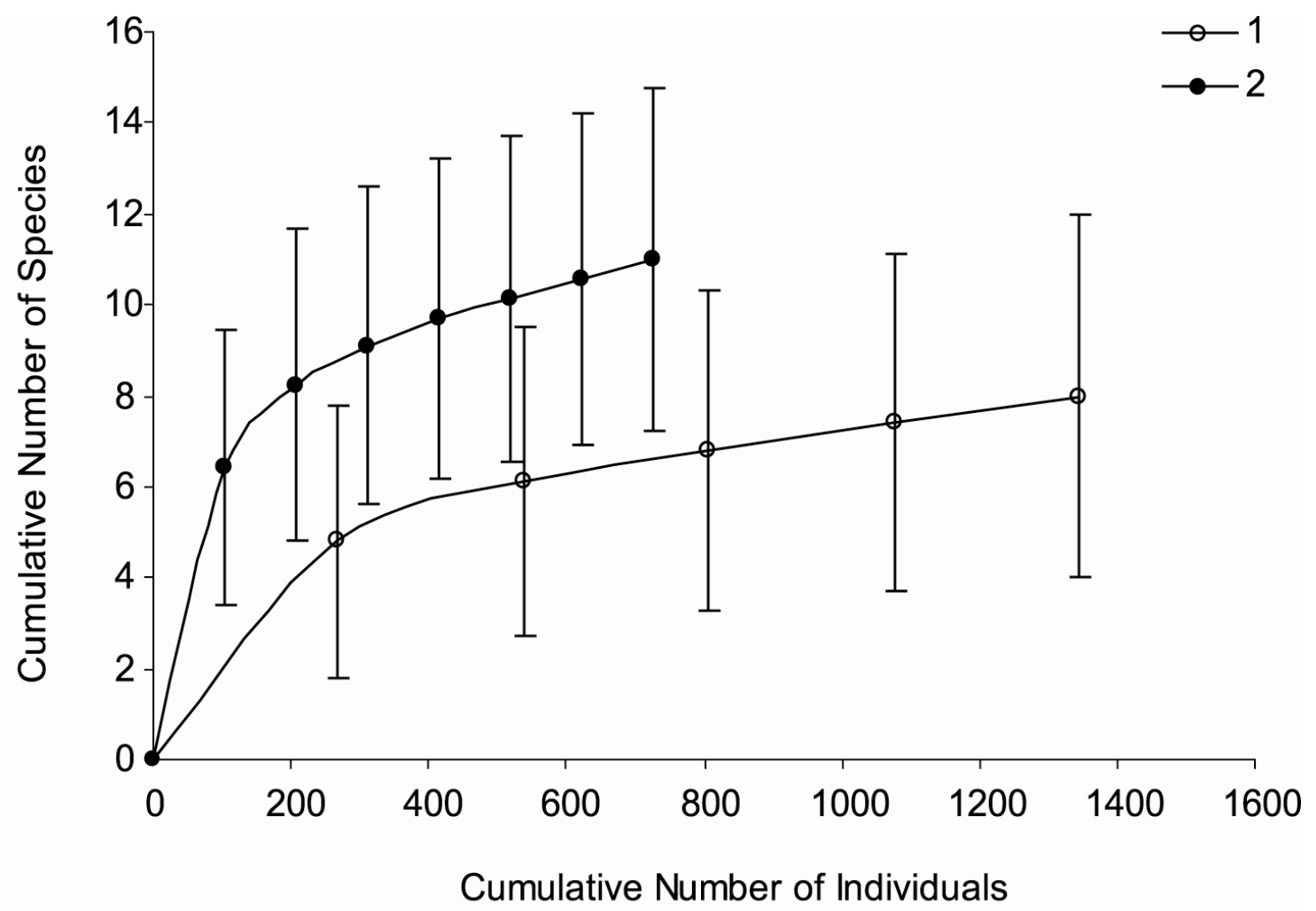

Figure 2 
Sample G12-a

Sample G2-a*

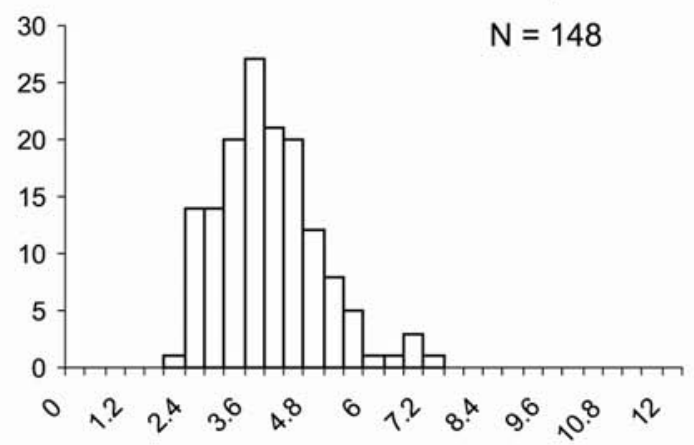

Sample P1-a $\mathrm{N}=155$
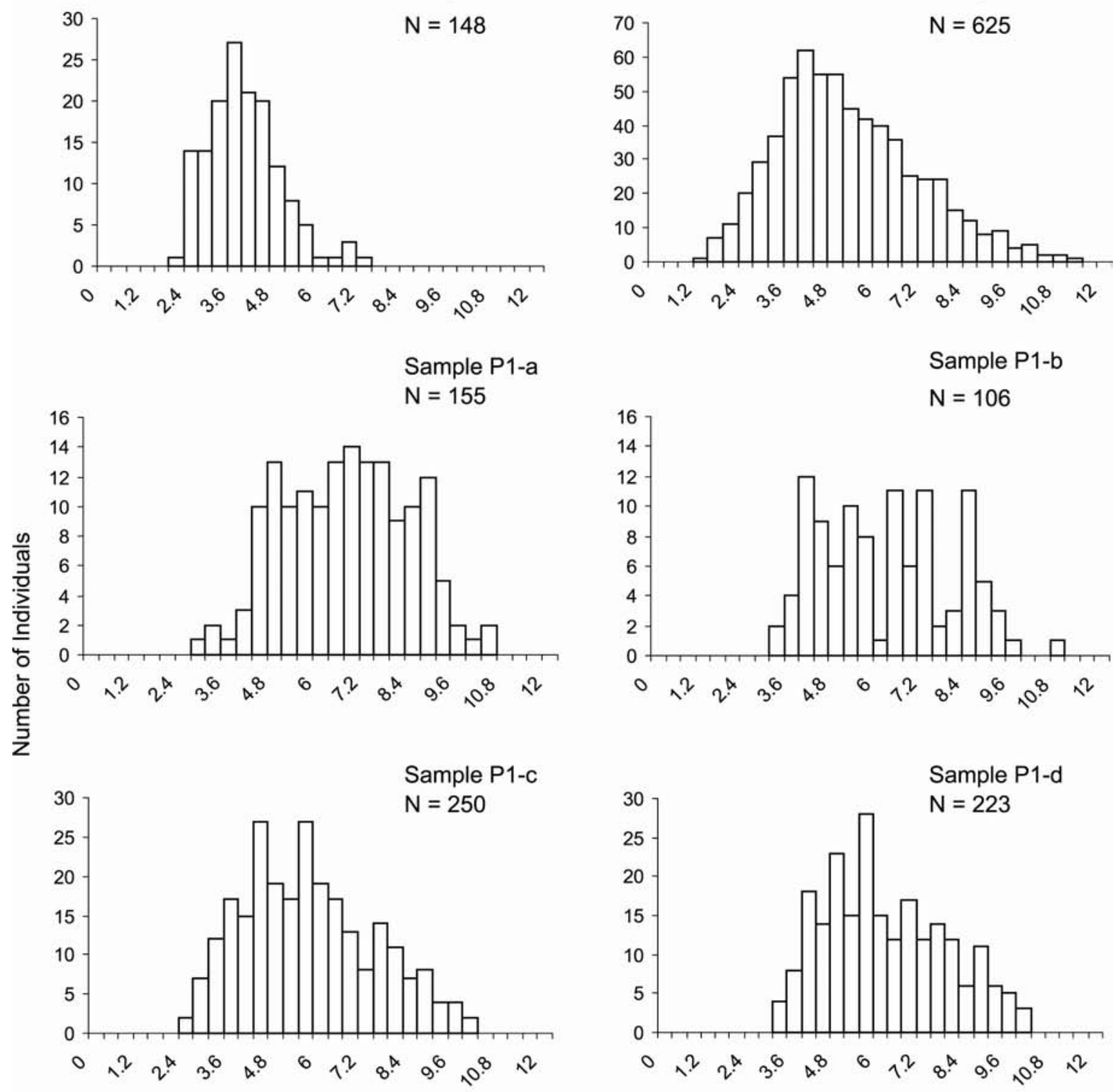

Sample P1-b
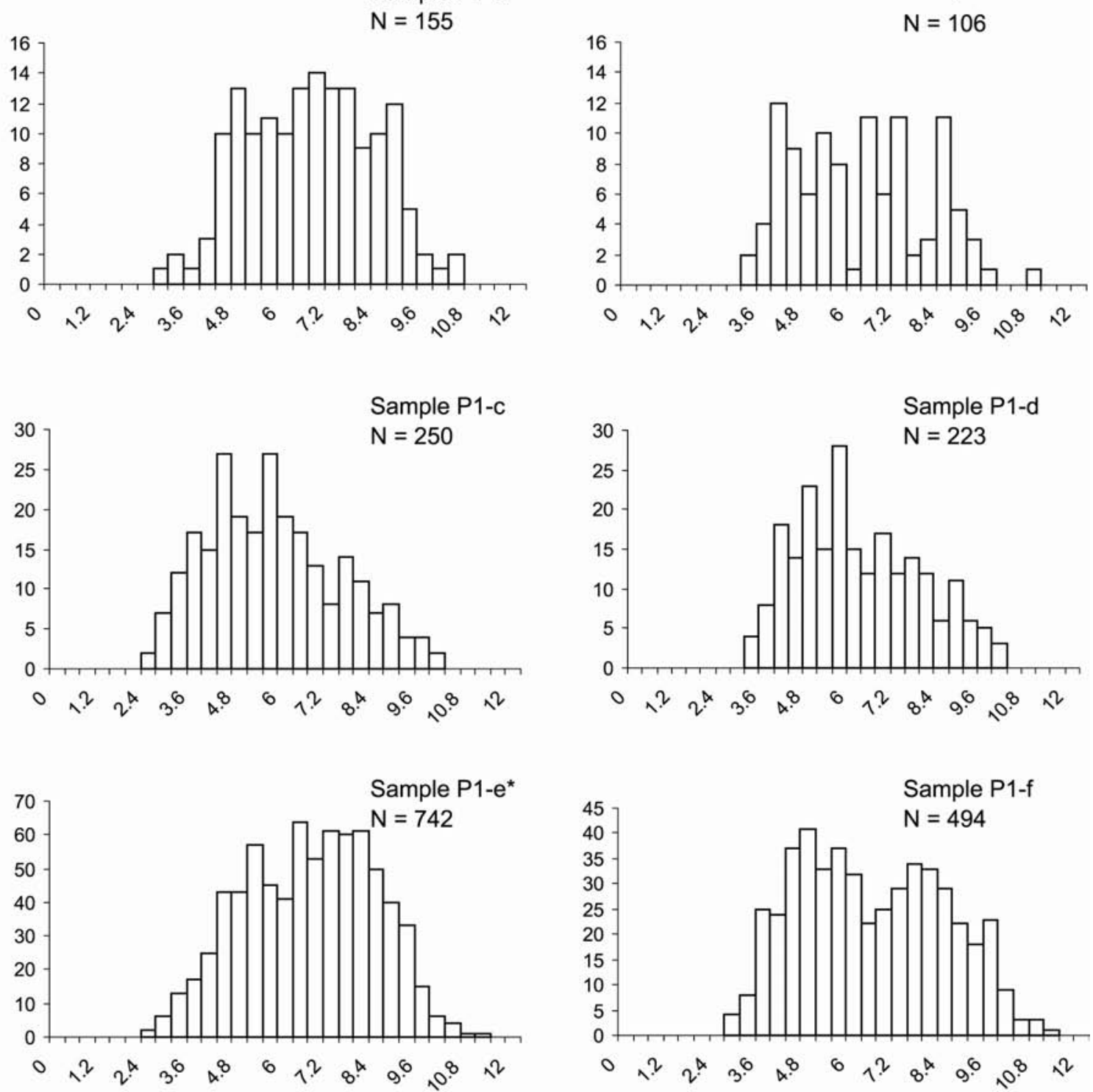

Curvilinear shell length (mm)

Figure 3 


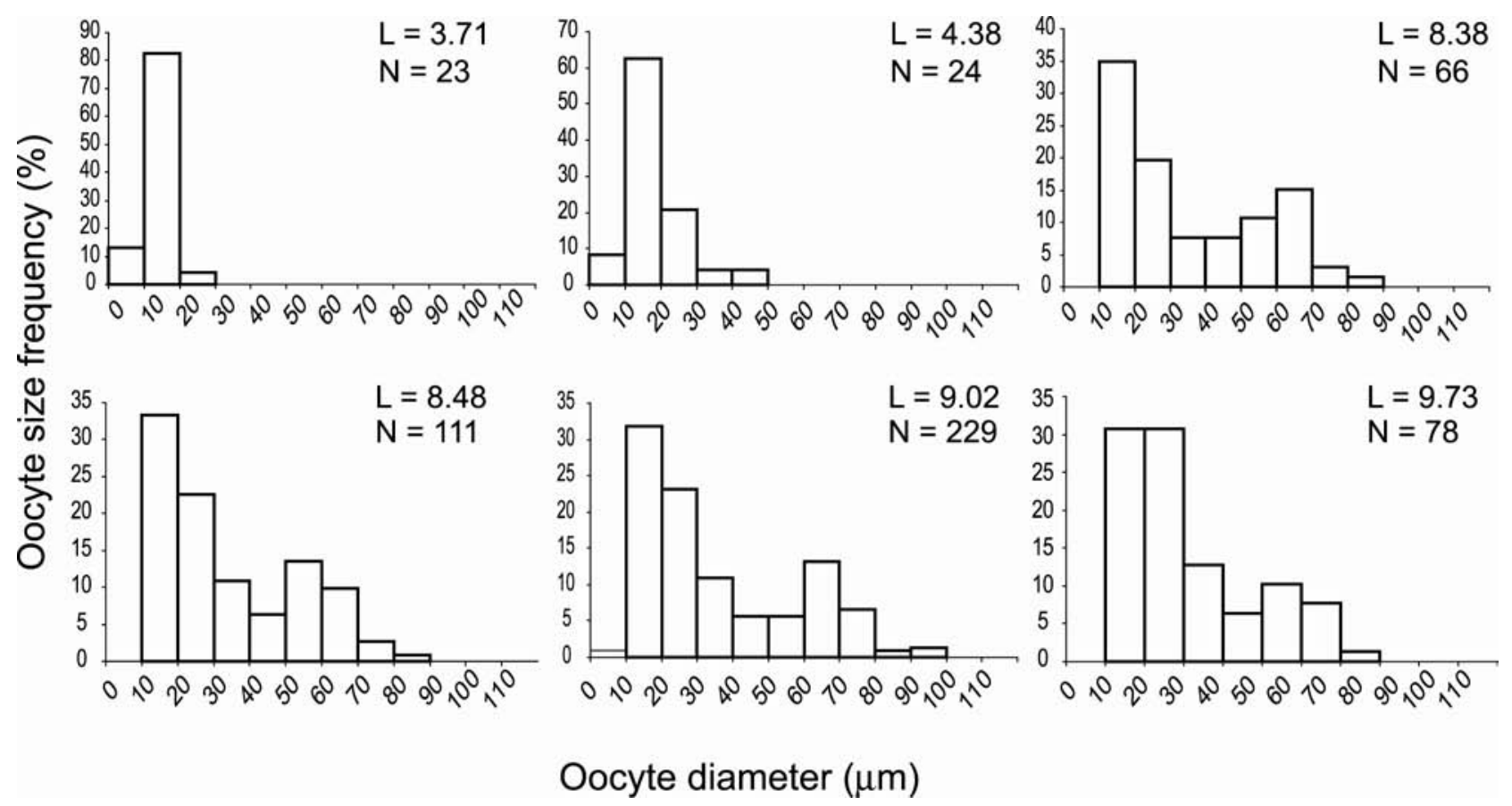

Figure 4 

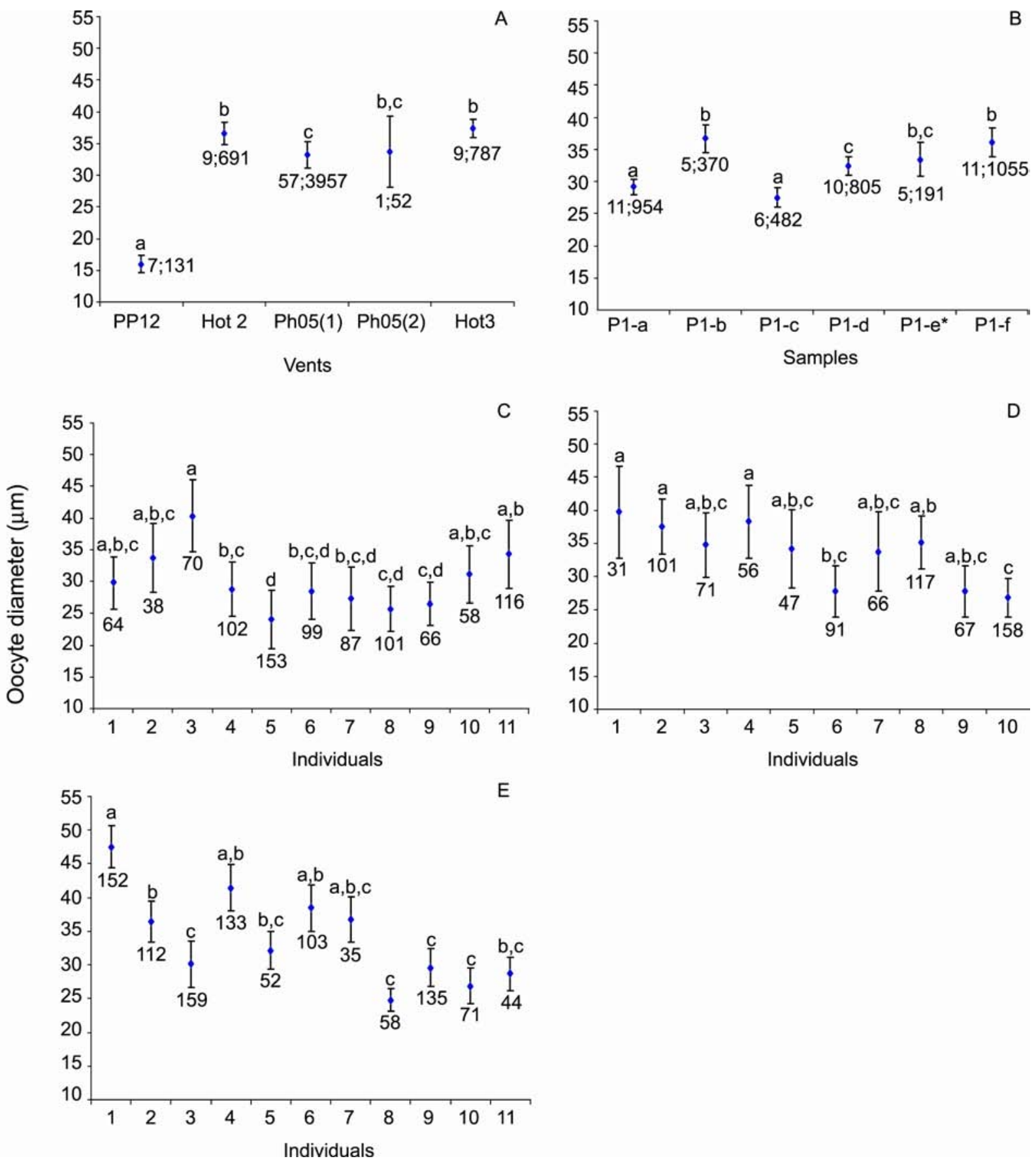

Figure 5 


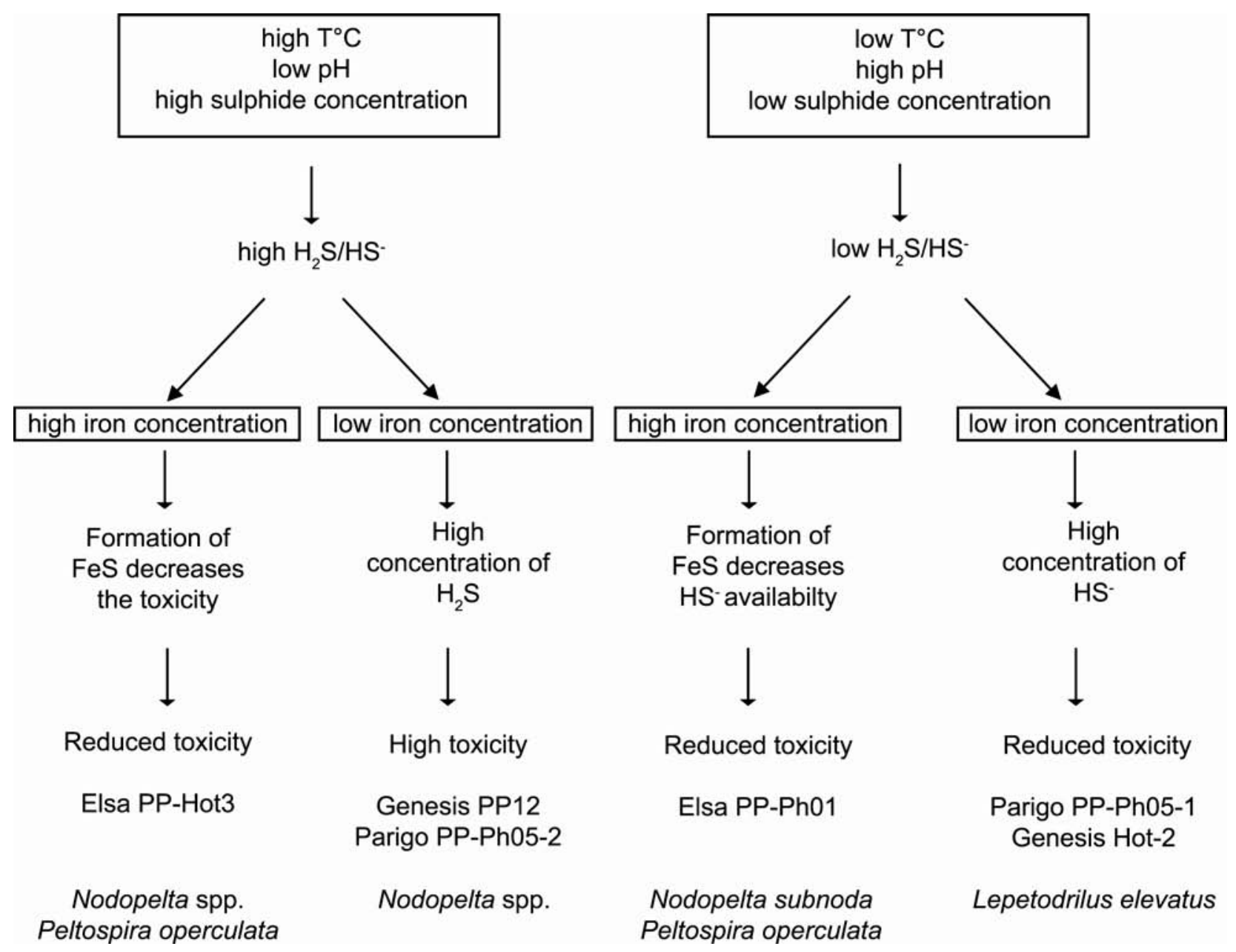

\section{Figure 6}

